\title{
A morphological and molecular review of the genus Goniurosaurus, including an identification key
}

Hai Ngoc NGO ${ }^{1}$, Huy Quoc NGUYEN ${ }^{2}$, Hieu Minh TRAN ${ }^{3}$, Hanh Thi NGO ${ }^{4}$, Minh Duc LE ${ }^{5}$, Laurenz Rafael GEWISS ${ }^{6}$, Mona van SCHINGEN-KHAN ${ }^{7}$, Truong Quang NGUYEN ${ }^{8, *}$ \& Thomas ZIEGLER ${ }^{9, *}$

${ }^{1,2}$ Vietnam National Museum of Nature, Vietnam Academy of Science and Technology,

18 Hoang Quoc Viet Road, Hanoi, Vietnam.

${ }^{2,8}$ Graduate University of Science and Technology, Vietnam Academy of Science and Technology, 18 Hoang Quoc Viet Road, Hanoi, Vietnam.

${ }^{3,8}$ Institute of Ecology and Biological Resources, Vietnam Academy of Science and Technology, 18 Hoang Quoc Viet Road, Hanoi, Vietnam.

${ }^{4}$ Department of Genetics, Faculty of Biology, University of Science, Vietnam National University Hanoi, 334 Nguyen Trai Road, Hanoi, Vietnam.

${ }^{4,5}$ Central Institute for Natural Resources and Environmental Studies, Vietnam National University Hanoi, 19 Le Thanh Tong, Hanoi, Vietnam.

${ }^{5}$ Department of Environmental Ecology, Faculty of Environmental Sciences, University of Science, Vietnam National University Hanoi, 334 Nguyen Trai Road, Hanoi, Vietnam.

${ }^{5}$ Department of Herpetology, American Museum of Natural History, Central Park West at $79^{\text {th }}$ Street, New York, USA.

${ }^{1,6,9}$ Institute of Zoology, University of Cologne, Zülpicher Strasse 47b, 50674 Cologne, Germany. ${ }_{1,6,9}$ Cologne, Germany Cologne Zoo, Riehler Straße 173, 50735 Cologne, Germany.

${ }^{7}$ Federal Agency for Nature Conservation, CITES Scientific Authority, Konstantinstrasse 110, 53179 Bonn, Germany.

*Corresponding authors: nqt2@yahoo.com; ziegler@koelnerzoo.de

1Email: ngohai2709@gmail.com

2Email: huynguyen17295@gmail.com

${ }^{3}$ Email: tranminhhieu t60@hus.edu.vn

${ }^{4}$ Email: ngohanhhus@gmail.com

${ }^{5}$ Email: minh.le.cres@gmail.com

${ }^{6}$ Email: lgewiss@smail.uni-koeln.de

${ }^{7}$ Email: Mona.van.Schingen-Khan@bfn.de

${ }^{1}$ urn:1sid:zoobank.org:author:91BE5B7A-2ECC-4FEC-B087-C47BC074492A

${ }^{2}$ urn:lsid:zoobank.org:author:0B5CC3D1-D8D5-41CD-9DC3-9F9B7FA3CE82

${ }^{3}$ urn:lsid:zoobank.org:author:FA82E6B8-3B50-4E6C-90FB-3FF1DD98CBD7

${ }^{4}$ urn:lsid:zoobank.org:author:5F0DA41F-0566-4738-A2F1-0A7D7E6A37DB

${ }^{5}$ urn:1sid:zoobank.org:author:785D605E-6A6F-4A67-BD18-7F40F426FC2C

${ }^{6}$ urn:1sid:zoobank.org:author:9AF54639-2BA0-47DE-BDC3-7816F57971A8

${ }^{7}$ urn:1sid:zoobank.org:author:ECC52912-B0CA-4C7C-AB16-BCAF83866E19

${ }^{8}$ urn:Isid:zoobank.org:author:822872A6-1C40-461F-AA0B-6A20EE06ADBA

${ }^{9}$ urn:lsid:zoobank.org:author:5716DB92-5FF8-4776-ACC5-BF6FA8C2E1BB 


\begin{abstract}
The genus Goniurosaurus (tiger geckos) currently consists of 23 species distributed in China, Japan and Vietnam. Several species complexes and recent discoveries of cryptic species pose challenges to the species identification, which is crucial to effectively implement the recent listing of the species from China and Vietnam in CITES Appendix II and the species from Japan in CITES Appendix III. Based on the results of our field work in northern Vietnam and data compiled from literature, we herein provide a taxonomic review of the genus Goniurosaurus. Our phylogenetic analyses showed that all recorded populations of tiger geckos from Vietnam, which were found to be monophyletic with low intra-specific genetic divergences, are assigned to one of the four species: G. catbaensis, G. huuliensis, G. lichtenfelderi or G. luii. Both genetic and morphological analyses confirm that the species from China and Vietnam can be split into three major groups. Based on the newly collected data, we provide an extended morphological description of the Vietnamese species. In addition, we provide an identification key for all Goniurosaurus species from China, Japan and Vietnam in order to assist authorities in the enforcement of the recent CITES listing.
\end{abstract}

Keywords. CITES enforcement, morphology, molecular phylogeny, taxonomy, tiger geckos.

Ngo H.N., Nguyen H.Q., Tran H.M., Ngo H.T., Le M.D., Gewiss L.R., Schingen-Khan M. van, Nguyen T.Q. \& Ziegler T. 2021. A morphological and molecular review of the genus Goniurosaurus, including an identification key. European Journal of Taxonomy 751: 38-67. https://doi.org/10.5852/ejt.2021.751.1379

\title{
Introduction
}

The eublepharid genus Goniurosaurus Grismer, Viets \& Boyle, 1999 (tiger geckos) currently consists of 23 species associated with granitic or karst formations in Southeast and East Asia. This genus shows a high level of local endemism and most tiger gecko species have been only recorded from a single locality, within unique ecosystems or an isolated archipelago (Orlov et al. 2008; Ziegler et al. 2008; Yang \& Chan 2015; Honda \& Ota 2017; Zhou et al. 2018; Ngo et al. 2019a; Qi et al. 2020a, 2020b; Zhu et al. 2020a, 2020b). The complex topography and variable climatic conditions throughout the distribution range of the genus may account for the disjunct distribution and occupation of different ecological niches by distinct populations. These factors may have driven natural selection, morphological diversification and phylogenetic evolution within this genus (Vitt et al. 1997; Clements et al.2006; Sexton et al. 2009; Gomes et al. 2016; Liang et al. 2018; Qi et al. 2020a, 2020b). According to recent morphological and molecular analyses, the genus Goniurosaurus is split into four species groups, namely the G. lichtenfelderi group with five species from both mainland and islands in China and Vietnam; the G. kuroiwae group containing six species from the Ryukyu Archipelago, Japan; the G. luii group comprising eight species distributed throughout islands and mainland in Vietnam and China; and the G. yingdeensis group consisting of four species from China (Nguyen et al. 2009; Nguyen 2011; Wang et al. 2013; Honda \& Ota 2017; Liang et al. 2018; Qi et al. 2020a, 2020b; Zhu et al. 2020a, 2020b). However, the systematics of the genus Goniurosaurus remains challenging due to ongoing discoveries of further cryptic species and the fact that there is not a single genetic marker that covers all 23 species, precluding a complete generic phylogeny of the group. Five subspecies of the G. kuroiwae group from Japan were reinstated at full species status and a new species, G. sengokui (Honda \& Ota, 2017), was recently discovered from the Ryukyu Archipelago (Honda \& Ota 2017). In China, two taxa, previously identified as G. luii Grismer, Viets \& Boyle, 1999, were described as distinct species, namely G. kadoorieorum Yang \& Chan, 2015 and G. kwangsiensis Yang \& Chan, 2015 (Yang \& Chan 2015), and a sister species of G. araneus Grismer, Viets \& Boyle, 1999, namely G. gezhi Zhu, He \& Li, 2020, was recently discovered (Zhu et al. 2020a). These three species occur in Southwest Guangxi Province (Zhu et al. 2020a). Four additional species, namely G. kwanghua Zhu \& He, 2020 and G. zhoui Zhou, Wang, Chen \& Liang, 2018, belonging to the G. lichtenfelderi group, as well as G. gollum Qi, Wang, Grismer, Chen, Lyu \& Wang, 2020 and G. varius Qi, Grismer, Lyu, 
Zhang, Li \& Wang, 2020 of the G. yingdeensis group, were recently described from China (Zhou et al. 2018; Qi et al. 2020a, 2020b; Zhu et al. 2020b).

To date, five species of Goniurosaurus are reported from Vietnam, viz. G. araneus, G. catbaensis Ziegler, Nguyen, Schmitz, Stenke \& Rösler, 2008, G. huuliensis Orlov, Ryabov, Nguyen, Nguyen \& Ho, 2008, G. lichtenfelderi (Mocquard, 1897) and G. luii (Grismer et al. 1999; Vu et al. 2006; Orlov et al. 2008; Ziegler et al. 2008; Nguyen et al. 2009; Nguyen 2011). All species were described based only on a few specimens and a small set of diagnostic characters. As such, phenotypic variability among these species may lead to the misidentification of taxa. For example, Orlov \& Darevsky (1999) described a new species (G. murphyi) based on a juvenile specimen, which was subsequently synonymized with G. lichtenfelderi by Grismer (2000). Ngo et al. (2016) documented another case with indistinct morphological differences between the newly described G. kadoorieorum and G. luii.

Due to habitat degradation and over-harvesting for the pet trade, wild populations of species of Goniurosaurus from China and Vietnam have been subject to severe declines (Stuart et al. 2006; Yang \& Chan 2015; Ngo et al. 2019b). Therefore, all Chinese and Vietnamese tiger gecko species have recently been included in CITES (Convention on International Trade in Endangered Species of Wild Fauna and Flora) Appendix II (CITES 2019; Ngo et al. 2019b). To effectively enforce relevant national and international regulations and to enable sustainable trade in CITES listed species, a detailed guideline for species identification is an essential prerequisite, especially as trade in the morphologically similar species from Japan is currently regulated under a lower protection level, namely CITES Appendix III (CITES Notification No. 2020/068). A proper identification guidance will help to prevent certain taxa from being traded under a wrong name to circumvent trade restrictions.

In this study, phylogenetic analyses were performed across all recorded populations of Goniurosaurus from Vietnam and along with other species from China and Japan using a fragment of the mitochondrial Cytochrome $b$ gene. Based on newly collected data from Vietnam, we expanded morphological descriptions of each species and evaluated intra- and inter-specific morphological variations among the species of Goniurosaurus. We further compared morphological data of Vietnamese tiger geckos with those from China and identified characters that can distinguish the Japanese species. We thereby provide an identification key for all Goniurosaurus species from China, Japan and Vietnam, in order to assist CITES enforcement authorities in species identification.

\section{Material and methods}

\section{Field surveys}

Field surveys were conducted in June and August 2014, May 2015, July 2016, June and July 2017, April 2018, from April to September 2019, as well as in June and July 2020 in Vietnam. Surveys were conducted for G. catbaensis in Hai Phong City and Quang Ninh Province, for G. huuliensis in Lang Son Province, for G. lichtenfelderi in Hai Duong, Bac Giang and Quang Ninh provinces, and for G. luii in Cao Bang and Lang Son provinces. Animals were captured by hand and subsequently released at the same sites after taking measurements and photos in life. Coordinates of each captured individual were recorded using a GPS device (Garmin GPSmap64, WGS84 datum) and can be shared upon request to the authors.

In addition, several vouchered specimens and small tissue samples of Goniurosaurus deposited in collections of the Institute of Ecology and Biological Resources (IEBR), Vietnam National Museum of Nature (VNMN) and Hanoi University of Science (HUS), Hanoi, Vietnam, were examined for morphological characters and molecular phylogeny. 


\section{Molecular data and phylogenetic analyses}

All taxa of the genus Goniurosaurus from China, Japan, and Vietnam, for which Cytochrome b data were available in GenBank, were included in the study. Three species, Gekko chinensis (Gray, 1842) (NC027191), Coleonyx mitratus Peters, 1863 (AB853481) and Holodactylus africanus Boettger, 1893 (AB853482), were used as outgroups following Honda et al. (2014).

Small tissue samples were collected from the tail tip of 18 wild specimens from representative localities in Vietnam and preserved separately in 70\% ethanol (Merck, Germany). The mitochondrial DNA Cytochrome b (cytb) gene was selected for DNA sequencing. The total genomic DNA was extracted using GeneJet Genomic DNA Purification (ThermoFisher Scientific, Lithuania), following protocols by the manufacturer's instructions. PCR reactions were performed using HotStar Taq Mastermix (Qiagen, Germany) to amplify a fragment of approximately $1000 \mathrm{bps}$ of cytb. The primer pair used for this study was L14731 (5'-TGGTCTGAAAAACCATTGTTG-3'; Honda et al. 2014) and GoniR1 (5'CTACGGGCTGTCCTCCGATTCAGGTT-3'; this study). The PCR volume consisted of $21 \mu \mathrm{l}: 2 \mu \mathrm{l}$ of each primer, $5 \mu 1$ water, $10 \mu 1$ of Taq mastermix and 1-2 $\mu 1$ DNA template depending on the quality of DNA in the final extraction solution. The PCR was performed at $95^{\circ} \mathrm{C}$ for 15 minutes, followed by 35 cycles, for $30 \mathrm{~s}$ at $95^{\circ} \mathrm{C}, 45 \mathrm{~s}$ at $48^{\circ} \mathrm{C}$ and $60 \mathrm{~s}$ at $72^{\circ} \mathrm{C}$ with a final elongation step for 6 minutes at $72^{\circ} \mathrm{C}$. Negative and positive controls were used for all DNA extractions and PCR reactions.

PCR products were visualized using electrophoresis through a $1 \%$ agarose gel, marker $1 \mathrm{~kb}, 1 \mathrm{X}$ TBE, stained with ethidium bromide and photographed under UV light. Successful amplifications were purified using GeneJet PCR Purification Kit (ThermoFisher Scientific, Lithuania). Cleaned PCR products were sent to $1^{\text {st }}$ Base (Malaysia) for sequencing in both directions.

The obtained sequences were aligned in Sequencher ver. 5.4 (Gene Codes Corp, Ann Arbor, MI, USA) and afterwards aligned using ClustalX ver. 2.1 (Thompson et al. 1997) with default settings. Data were analyzed using maximum parsimony (MP) as implemented in PAUP*4.0b10 (Swofford 2001) and Bayesian inference (BI) as implemented in MrBayes ver. 3.2 (Ronquist et al. 2012). Settings for these analyses followed Le et al. (2006), except that the number of generations in the Bayesian analysis was increased to $1 \times 10^{7}$. For the maximum likelihood (ML) analysis, we used IQ-TREE ver. 1.6.7.1 (Nguyen et al. 2015) with a single model and 10000 ultrafast bootstrap replications. The optimal model for nucleotide evolution was set to TPM1 uf $+\mathrm{I}+\mathrm{G}$ as selected by Jmodeltest ver. 2.1.4 (Posada et al. 1998). As the phylogenetic relationships between species and species groups were well resolved and virtually every important node received high statistical support from all analyses, we opted not to partition our data by codon positions.

For the Bayesian analysis, we used the optimal model determined by Jmodeltest with parameters estimated by MrBayes ver. 3.2.7. Four Markov chains, one cold and three heated utilizing default heating values, were sampled every 1000 generations. Log-likelihood scores of sample points were plotted against generation time to detect stationarity of the Markov chains. The burn-in value was set to 50 in the BI analysis, as - $\operatorname{lnL}$ scores reached stationarity after 50000 generations in both runs. Nodal support was evaluated using Bootstrap replication (BP) as estimated in PAUP*4.0b10 and ultrafast BP in IQ-TREE ver. 1.6.7.1 and posterior probability (PP) in MrBayes ver. 3.2. BP $\geq 70$ (Hillis \& Bull 1993) and ultrafast $\mathrm{BP}$ (UBP) and $\mathrm{PP} \geq 95 \%$ are regarded as strong support for a clade (Ronquist et al. 2012; Nguyen et al. 2015). The uncorrected pairwise distance (p) were calculated in PAUP*4.0b10.

\section{Morphological analyses}

A total of 486 live individuals and 54 museum specimens of four species from Vietnam were examined for morphological data, comprising 194 individuals of G. catbaensis (21 juveniles, 93 females and 80 males), 80 individuals of $G$. huuliensis (02 juveniles, 46 females and 32 males), 178 individuals of 
G. lichtenfelderi (14 juveniles, 72 females and 92 males), and 88 individuals of G. luii (11 juveniles, 43 females and 34 males). Detailed descriptions of each species were based on newly collected data combined with previous literature for the morphological variation, such as for $G$. catbaensis from Ziegler et al. (2008) and Nguyen (2011), for G. huuliensis from Orlov et al. (2008) and Nguyen (2011), for G. lichtenfelderi from Grismer (2000), Grismer et al. (2002) and Nguyen (2011), and for G. luii from Grismer et al. (1999), Vu et al. (2006) and Nguyen (2011). No specimen of G. araneus was investigated in this study, however, we included morphological data of eight specimens from the type locality in Cao Bang Province, Vietnam and Guangxi Province, China from the literature (Grismer et al. 1999; Chen et al. 2014). The sex of each collected specimen was determined based on the presence (in males) or absence (in females) of large swollen hemipenial bulges. Lizards were categorized into two age classes based on the snout-vent length ( $G$. lichtenfelderi: $\mathrm{SVL}<80 \mathrm{~mm}=$ juveniles, $\mathrm{SVL} \geq 80 \mathrm{~mm}=$ adults, while three other species of Goniurosaurus were sorted with $\mathrm{SVL}<85 \mathrm{~mm}=$ juveniles, $\mathrm{SVL} \geq 85 \mathrm{~mm}=$ adults).

Measurements were taken with dial calipers to the nearest $0.1 \mathrm{~mm}$ at the right side of each individual.

\section{Abbreviations}

$\mathrm{AD}=$ diameter of auditory meatus

$\mathrm{AG}=$ axilla to groin length, from posterior edge of forelimb insertion to anterior edge of hindlimb insertion

$\mathrm{BH}=$ maximum body height, from top of dorsal body to belly

$\mathrm{BW}=$ maximum body width, greatest width of torso, taken at level of midbody

$\mathrm{CH}=$ cheek height, from posterior edge of labial to top of head at parietal region

$\mathrm{ED}=$ diameter of eye, greatest diameter of orbit

$\mathrm{EE}=$ eye to ear distance, from posterior margin of eye to posterior margin of ear

FLL $=$ forelimb length, from axilla to the tip of the fourth finger

$\mathrm{HH}=$ maximum head height

$\mathrm{HL}=$ head length, from the tip of snout to posterior edge of occiput

HLL $=$ hindlimb length, from groin to the tip of the fourth toe

$\mathrm{HW}=$ maximum head width

IO1 = interorbital distance, distance between anteriormost points of eyes

IO2 = interorbital distance, distance between posteriormost points of eyes

ML = mouth length, from tip of snout to last posterior labial edge

MW $=$ mouth width, distance between last posterior labial edges on each side

$\mathrm{ND}=$ supranasal distance, distance between nares

$\mathrm{SE}=$ snout to eye distance, measured from tip of snout to anteriormost point of eye

SVL $=$ snout-vent length, from tip of snout to vent

$\mathrm{TaL}=$ tail length, from vent to tip of tail

$\mathrm{WT}=$ maximum tail width

\section{Scale counts}

CIL = eyelid fringe scales or ciliaria

DTR $=$ dorsal tubercle rows at midbody

$\mathrm{GP}=$ gular scales bordering the postmentals

GST $=$ granular scales surrounding dorsal tubercles

IFL $=$ infralabials

IN $=$ postrostrals or internasals

LD1 = subdigital lamellae under the first finger

LD4 = subdigital lamellae under the fourth finger

LT1 = subdigital lamellae under the first toe 


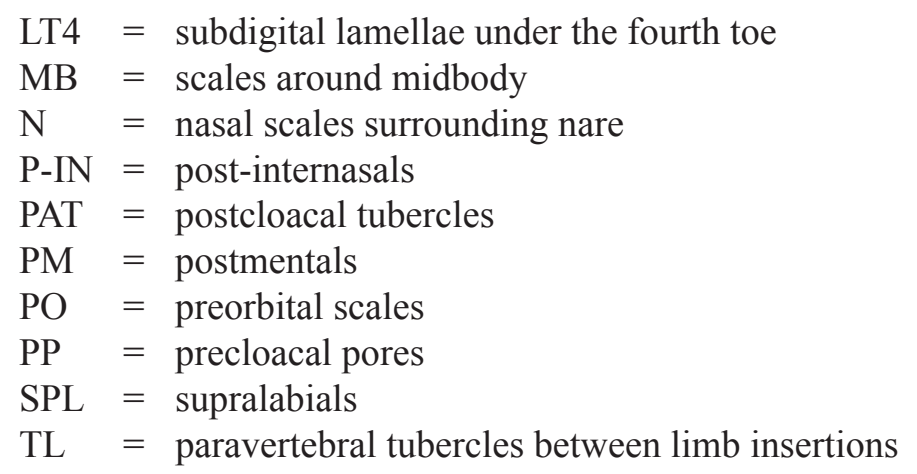

Statistical analyses were performed by using the software environment R.3.1.2 (RStudio Team 2018). Shapiro-Wilk's test was used to test the assumption of normality. Kruskal-Wallis's test was performed to determine differences concerning the SVL of sex and age classes among species, as well as the extracted PC1 and PC2 values (mentioned below) of a principal component analysis among four tiger gecko species in Vietnam except of $G$. araneus. For both tests we applied $p=0.05$. The SVL variable was excluded from subsequent analyses due to high collinearity with other dimensions. We further performed a Principal Component Analysis (PCA) of $\log _{10}$-transformed raw data of 18 remaining morphometric characters (except TaL and WT variables, due to many regenerated tails), using the packages "factoextra" and "FactoMinerR" to detect variances among the four selected Vietnamese species via contribution percentage of the PC1 and other PCs scores (Kassambara 2017). Morphometric variation of each species was illustrated by representatively clustered ellipse spaces with different coded-color within a spatial coordinate of the first two most important dimensions (PC1 and PC2) in the PCA analysis, to visually evaluate the overlap among the four species. In addition, we identified the overall difference in meristic characters among the 17 tiger gecko species native to China and Vietnam assigned to three groups (G. lichtenfelderi, G. luii and G. yingdeensis) by using a Multiple Correspondence Analysis (MCA). The meristic variation among the three groups was also visualized by convex ellipses within a spatial coordinate of the first two most important dimensions (Dim1 and Dim2) in the MCA analysis.

\section{Results}

\section{Molecular phylogeny}

The final matrix consisted of 949 bp aligned characters with 48 sequences of 14 ingroup and three outgroup taxa. The alignment contained no gaps. In total, 404 characters were found to be parsimony informative. The MP analysis produced 624 most parsimonious trees with 1404 steps $(\mathrm{CI}=0.54, \mathrm{RI}=0.85)$. Our phylogenetic analyses recovered a generally similar topology to those reported by Liang et al. (2018) and Zhu et al. (2020a, 2020b). Specifically, the Goniurosaurus lichtenfelderi group and the G. luii group form a monophyletic group with high nodal values from all analyses and the G. kuroiwae group is sister to the other two. In addition, each species group was also strongly corroborated as monophyletic from all analyses (Fig. 1). Within each species group, the results supported by this study are more similar to those generated by Liang et al. (2018), because Zhu et al. (2020a) used a different mitochondrial marker, the $16 \mathrm{~S}$ ribosomal RNA gene. Nonetheless, we found several noted discrepancies between the two studies. Specifically, our phylogenetic analyses showed that G. kuroiwae (Namiye, 1912) is polyphyletic with high nodal support for each of the clades. In addition, $G$. luii was strongly corroborated as monophyletic in our Bayesian and $\mathrm{MP}$ analyses $(\mathrm{BP}=93 \%$; $\mathrm{PP}=98 \%)$, but only weakly recovered as monophyletic in Liang et al. (2018) ( $\mathrm{BP}=67 \% ; \mathrm{PP}=64 \%)$. Goniurosaurus lichtenfelderi was recovered as monophyletic with perfect nodal support from all analyses in our study, but $G$. hainanensis Barbour, 1908 is polyphyletic. On the other hand, both species are not monophyletic in Liang et al. (2018). The positions of G. zhoui and G. bawanglingensis Grismer, Haitao, Orlov \& Anajeva, 2002 are interchanged in the trees supported by the two studies with strong nodal support from Liang et al. (2018) and weak corroboration from 
ours. All surveyed sub-populations of Goniurosaurus from Vietnam were placed in four separate clades corresponding to four distinct species, G. catbaensis, G. huuliensis, G. luii and G. lichtenfelderi with significantly statistical support values, except for the ML analysis of $G$. luii $(\mathrm{UBP}=88 \%)$. Intra-specific genetic divergences of these species were relatively low: G. catbaensis $(0.7-1.6 \%)$, G. huuliensis $(0.4$ 1.2\%), G. lichtenfelderi (0-0.7\%), and G. luii (0-1.9\%) (Fig. 1; Supp. file 1: Table S1).

\section{Taxonomic accounts}

Class Squamata Oppel, 1811

Order Gekkota Cuvier, 1817

Family Eublepharidae Boulenger, 1883

Genus Goniurosaurus Grismer, Viets \& Boyle, 1999

Goniurosaurus araneus Grismer, Viets \& Boyle, 1999

\section{Diagnosis}

Body splayed and gracile, SVL 108.9-124.0 mm; external nares bordered by 6-8 nasal scales; supraorbital region with a row of enlarged tubercles; outer surface of upper eyelid composed of small granular

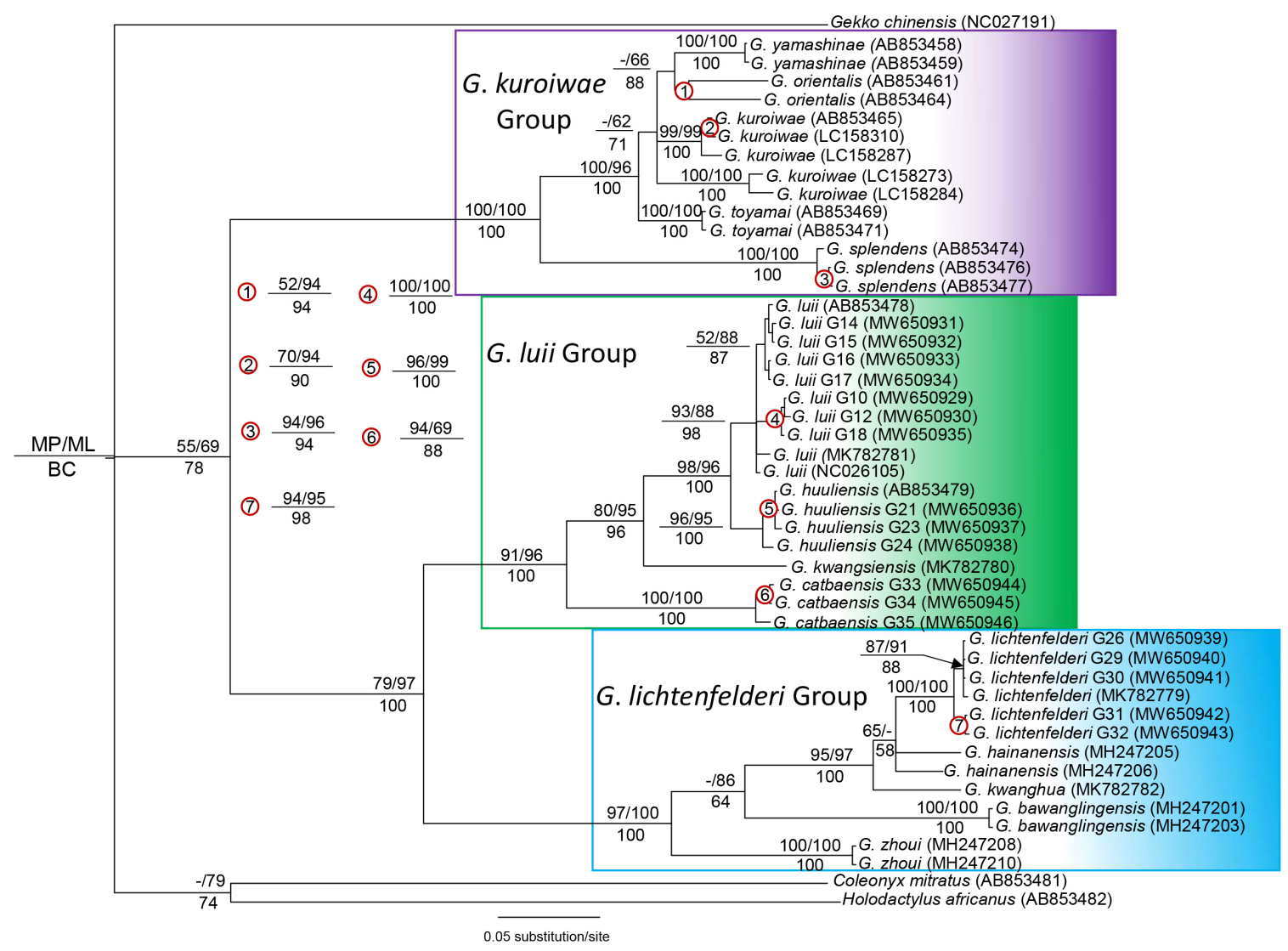

Fig. 1. Phylogram containing Goniurosaurus Grismer, Viets \& Boyle, 1999 representatives from China, Japan and Vietnam based on the Bayesian analysis. Numbers above and below branches are MP/ML ultrafast bootstrap values and combined Bayesian posterior probabilities, respectively. Dash represents $<50 \%$ value. 
scales, one-half the size of those on top of head; internasal single; supralabials $8-10$; infralabials 8 or 9 ; preorbital scales 13-18; eyelid fringe scales 52-67; postmentals 4-6; dorsal body scales elongate; paravertebral tubercles 29-38; scales around midbody 129-147; scales surrounding dorsal tubercles 1014; axillary pockets deep; subdigital lamellae under fourth toe 23-25; precloacal pores in males 18-23; iris dark brown; dorsal ground color of head, body and limbs immaculate dull yellow-gray; nuchal loop posteriorly protracted (in V-shape); dorsal body bands between limb insertions 3, wide, edged anteriorly and posteriorly by wide dark brown bands; light band on tail base in width of 15 or 16 granular scales; ground color of tail black, caudal bands 5, white, completed ventrally; ventral surface of head, body and limbs dull white and immaculate (Grismer et al. 1999; Nguyen 2011; Chen et al. 2014).

\section{Remarks}

During our field work in northern Vietnam, including the type locality in Cao Bang Province, no specimen of Goniurosaurus araneus was seen. Therefore, the diagnosis was solely based on the descriptions of Grismer et al. (1999) and Chen et al. (2014).

Goniurosaurus catbaensis Ziegler, Nguyen, Schmitz, Stenke \& Rösler, 2008 Fig. 2

\section{Diagnosis}

Body splayed and gracile, SVL $89.3-125.3 \mathrm{~mm}$; external nares bordered by 6-8 nasal scales; supraorbital region with a row of enlarged tubercles; outer surface of upper eyelid composed of granular scales, about the same size of those on top of head and with a row of 6-10 enlarged tubercles; internasals absent; supralabials 8-11; infralabials 7-10; eyelid fringe scales 45-56; postmentals 2-5; gular region below lower jaws without enlarged tubercles; paravertebral tubercles 31-38; scale rows around midbody 112 127 , granular scales surrounding tubercles $8-11$; axillary pockets deep; subdigital lamellae under fourth toe 22-25; precloacal pores in males 16-23; iris orange-brown; dorsal ground color of head, body and limbs gray-brown to pale brown and mottled with dark brown blotches; nuchal loop thin, posteriorly protracted (in V-shape); dorsal body bands between limb insertions 3-4, thin, yellow, without dark spots; light band on tail base in width of 8-9 scales; ground color of tail black, caudal bands 5 , white, completed ventrally; ventral surface of head, body and limbs dull white and immaculate, gular region with brown spots (modified after Ziegler et al. 2008; Nguyen 2011).

\section{Description (Supp. file 1: Table S2)}

Body splayed and gracile, adult males: SVL 92.9-125.3 mm (mean \pm SE: $112.3 \pm 0.8 \mathrm{~mm}, \mathrm{n}=80)$, TaL 7.2$97.9 \mathrm{~mm}(75.2 \pm 1.9 \mathrm{~mm})$; adult females: SVL 89.3-122.1 $\mathrm{mm}(111.8 \pm 0.8 \mathrm{~mm}, \mathrm{n}=93)$, TaL 17.5$98.3 \mathrm{~mm}(70.3 \pm 1.7 \mathrm{~mm})$; juveniles: SVL 53.4-78.8 mm (68.8 $\pm 1.8 \mathrm{~mm}, \mathrm{n}=21)$, TaL $11.8-61.2 \mathrm{~mm}$ $(48.1 \pm 2.6 \mathrm{~mm})$ (Supp. file 1: Table S2); head triangular, wider than neck, covered by uniform granular scales interspersed with tubercles in temporal and occipital regions; scales on rostrum slightly larger and flatter; enlarged supraorbital tubercles in a conspicuous row; middorsal portion of rostral partially sutured dorsomedially, bordered laterally by first supralabial on each side, dorsolaterally by prenasal on each side, and dorsally by two supranasals; internasal (postrostral) scales absent; external nares bordered by $6-8$ nasals: anteriorly by prenasal and supranasal, dorsally by supranasal, posteriorly by two slightly enlarged postnasals and 1 or 2 smaller granular scales, and ventrally by prenasal; prenasals with long recurved ventral portion; supranasals triangular, meeting in midline behind rostral suture; preorbital scales 10-13; supralabials 8-11; infralabials $7-10$; eyes relatively large, pupils vertical; eyelid fringe scales 45-56, those of upper eyelid slightly enlarged; outer surface of upper eyelid composed of granular scales of about the same size of those on top of head, including a row of 6-10 enlarged tubercles; fold of skin originating from suborbital region extends posteroventrally across angle of jaw; external auditory meatus elliptical with long axis directed dorsoventrally; tympanum deeply recessed; mental triangular, 


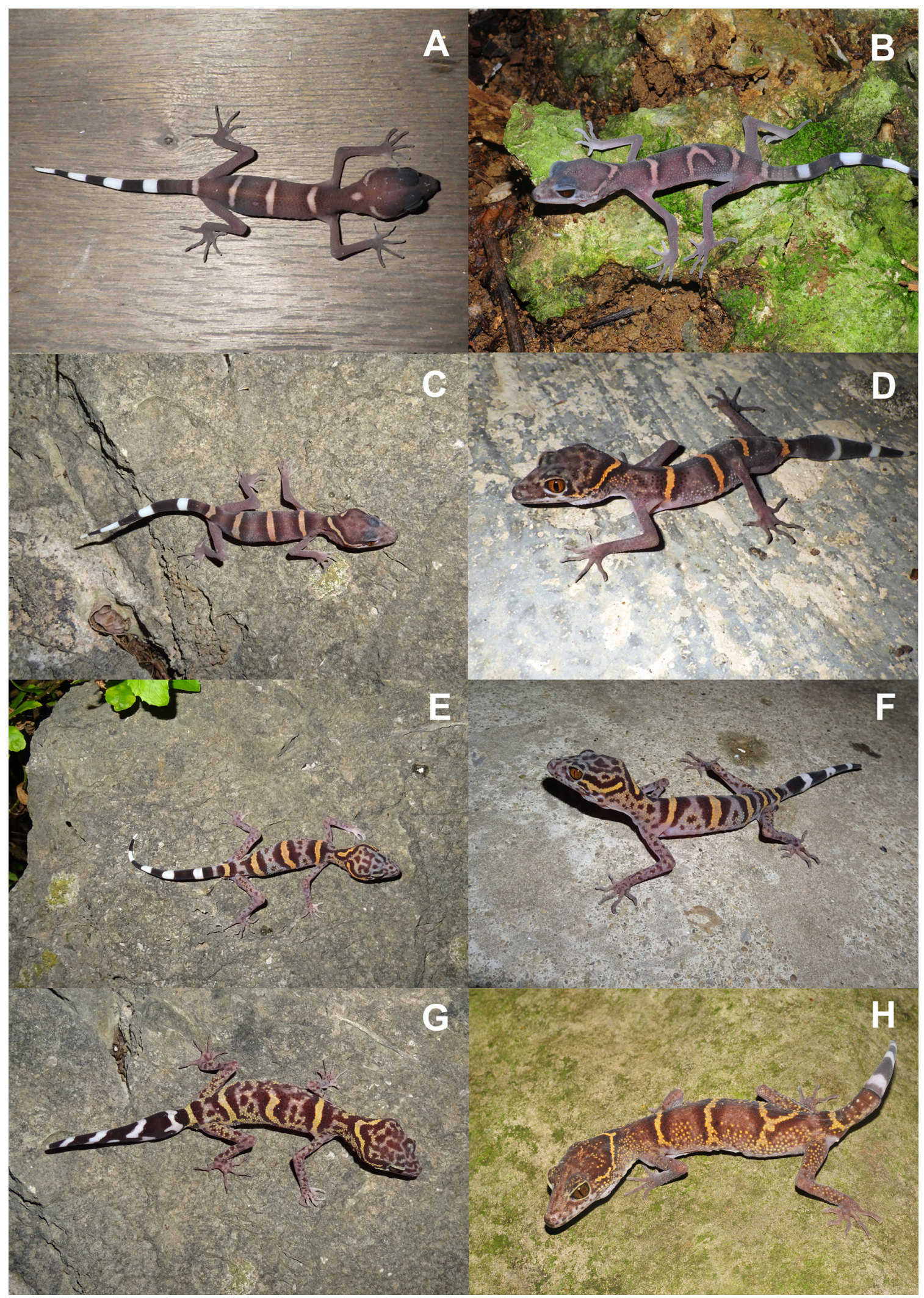

Fig. 2. Goniurosaurus catbaensis Ziegler, Nguyen, Schmitz, Stenke \& Rösler, 2008. A. Juvenile $(\mathrm{SVL}=55 \mathrm{~mm})$. B. Juvenile $(\mathrm{SVL}=69 \mathrm{~mm})$. C. Juvenile $(\mathrm{SVL}=75 \mathrm{~mm})$. D. Adult $(\mathrm{SVL}=91 \mathrm{~mm})$. E. Adult $(S V L=99 \mathrm{~mm})$. F. Adult $(\mathrm{SVL}=105 \mathrm{~mm})$. G. Adult $(\mathrm{SVL}=116 \mathrm{~mm})$. H. Adult $(\mathrm{SVL}=125 \mathrm{~mm})$. 
bordered laterally by first infralabial on each side and posteriorly by $2-5$ postmentals; postmentals bordered by 6-10 gular scales; gular region below lower jaws without enlarged tubercles; gular scales juxtaposed and granular, abruptly grading posteriorly into flat hexagonal pectoral scales and even larger ventral scales.

Neck narrower than body, covered with uniform granular scales interspersed with several sharply pointed conical tubercles on nape; tubercles on flanks conical, those of vertebral region somewhat lower in profile; dorsal body tubercles surrounded by 9-11 granular scales; dorsal tubercle rows at midbody 19-24; paravertebral tubercles between limb insertions 31-38, distinct vertebral row of tubercles absent; scales around midbody 112-127; larger ventral scales grade abruptly into smaller granular scales immediately anterior to vent at level of preanal pores; males with 18-23 precloacal pores in a transverse continuous series; region posterior to vent covered by flat juxtaposed scales and great hemipenial bulges, containing 2 or 3 enlarged postcloacal tubercles laterally on each side at level of vent; tail long and thin, thick at base, anteriorly with whorls; dorsal tail scales flat, smooth, up to 1.5 times the size of dorsal scales, arranged in more or less regular transverse rows; light band on tail base in width of 8-9 granular scales and with 7-8 tubercles in a transversal series; subcaudals larger than those on dorsal surface of tail.

Limbs relatively long and thin, covered dorsally with granular scales interspersed with several tubercles and ventrally with flat juxtaposed to subimbricate scales; dorsal granular scales grade into slightly flattened subimbricate scales on top of pes and manus; hind limbs slightly larger than forelimbs; larger granular scales on ventral surface of pes and manus; axillary pockets deep; subdigital lamellae wide, 9-11 under first finger, 18-21 under fourth finger, 9-12 under first toe, 22-25 under fourth toe; digits laterally compressed, increasing in length from first to fourth, fifth shorter than fourth (modified after Ziegler et al. 2008; Nguyen 2011).

\section{Coloration in life (Fig. 2)}

Dorsal ground color of head, body and limbs grey brown (in animals with SVL 53.4-105 mm) and blotches chestnut brown (in animals with SVL 110-125.3 mm), juveniles without small blotches, adults mottled with few circular blotches on body and limbs and long dark brown blotches on head; few yellow conical tubercles on franks of neck and body, and limbs in adults; iris light orange or red brown; five bands on the dorsal ground, thin, immaculate without dark spots, cream in juveniles and light orange or yellow in adults, all edged anteriorly and posteriorly by thin dark brown bands, including one thin nuchal loop extending from posterior corners of eyes and posteriorly protracted (in V-shape), three body bands between limb insertions, and another one on tail base; ground color of tail dark brown, and grey brown at mottled tail base; 3-5 immaculate white caudal bands, edged anteriorly and posteriorly in black; ventral surface of head, body and limbs dull white, juveniles absolutely immaculate, but adults with few dark spots on limbs, weak brown lateral spotting in gular region, venter and limbs.

Goniurosaurus huuliensis Orlov, Ryabov, Nguyen, Nguyen \& Ho, 2008

Fig. 3

\section{Diagnosis}

Body splayed and gracile, SVL 97.2-134.6 mm; external nares bordered by 6-8 nasal scales; supraorbital region with a row of enlarged tubercles; outer surface of upper eyelid composed of granular scales, about one half the size of those on top of head and without enlarged tubercles; internasal 1 or 2 (rarely absent); supralabials 9-12; infralabials 9-12; preorbital scales 14-20; eyelid fringe scales 51-59; postmentals 2-4; gular region below lower jaws with enlarged tubercles; paravertebral tubercles 31-37; scale rows around midbody 118-130, granular scales surrounding tubercles 11-13; axillary pockets deep; subdigital lamellae under fourth toe 21-25; precloacal pores in males 25-30; iris reddish brown; dorsal ground color of head, body and limbs dark brown, without small dark brown blotches (dark blotches present 
only on lower zone of flanks); nuchal loop thin, posteriorly protracted (in V-shape); dorsal body bands between limb insertions 3, thin, immaculate yellow; gular region with brown spots (modified after Orlov et al. 2008; Nguyen 2011).

Description (Supp. file 1: Table S2)

Body splayed and gracile, adult males SVL 97.2-132.2 mm (mean \pm SE: $118.9 \pm 1.4 \mathrm{~mm}, \mathrm{n}=32$ ), TaL 36.7-108.6 mm $(72.7 \pm 3.7 \mathrm{~mm})$, adult females SVL 97.4-134.6 mm $(121.1 \pm 1.2 \mathrm{~mm}, \mathrm{n}=46)$,

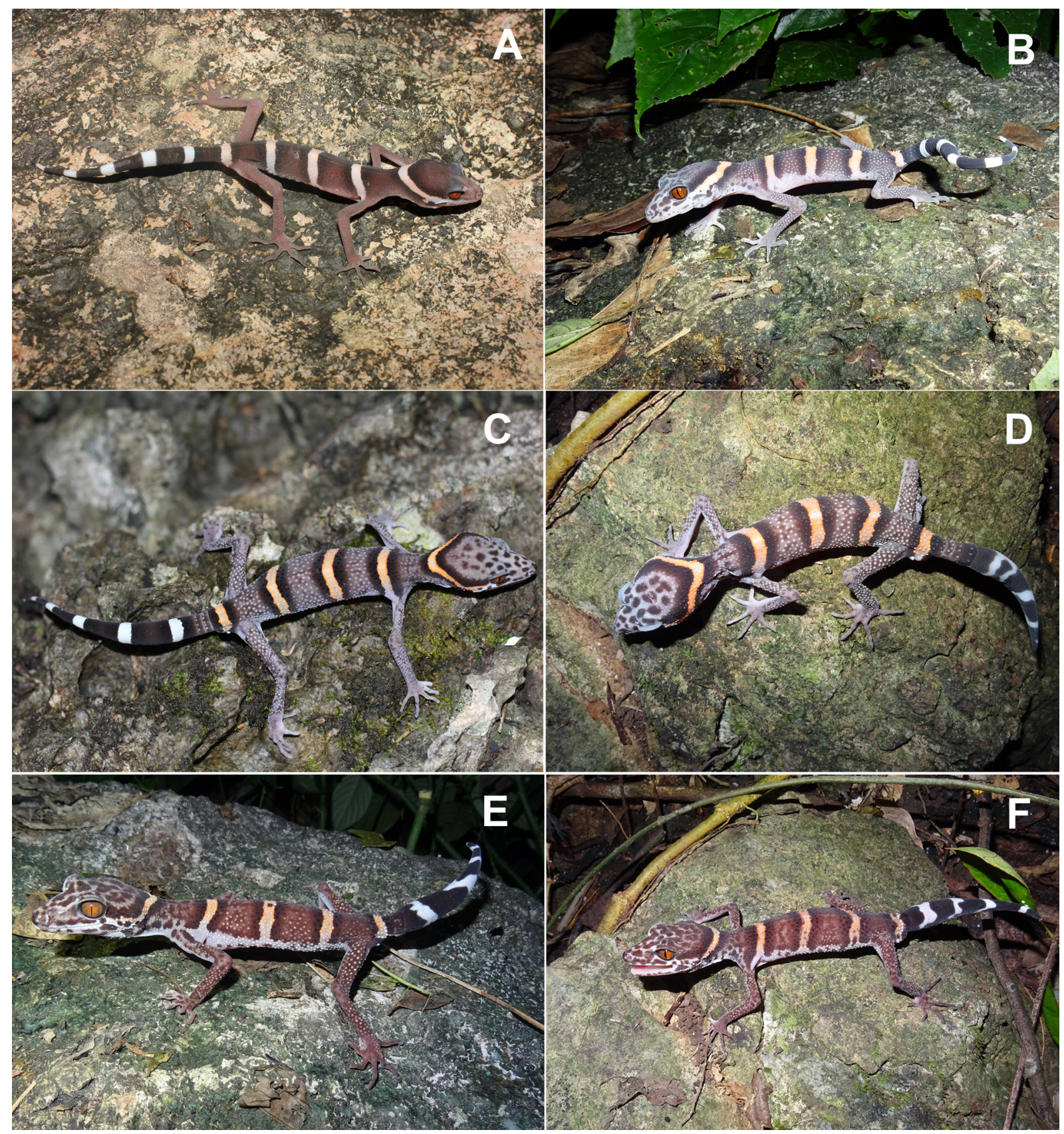

Fig. 3. Goniurosaurus huuliensis Orlov, Ryabov, Nguyen, Nguyen \& Ho, 2008. A. Juvenile $(\mathrm{SVL}=74.4 \mathrm{~mm})$. B. Adult $(\mathrm{SVL}=97 \mathrm{~mm})$. C. Adult $(\mathrm{SVL}=108 \mathrm{~mm})$. D. Adult $(\mathrm{SVL}=116 \mathrm{~mm})$. E. Adult $(\mathrm{SVL}=125 \mathrm{~mm})$. F. Adult $(\mathrm{SVL}=132 \mathrm{~mm})$. 
TaL 48.4-106.7 mm $(78.2 \pm 2.7 \mathrm{~mm})$, juveniles SVL 73.5-74.4 mm $(\mathrm{n}=2)$, TaL 62.5-62.7 mm (Supp. file 1: Table S2); head triangular, wider than neck, covered by uniform granular scales interspersed with tubercles in temporal and occipital regions; scales on rostrum slightly larger and flatter; enlarged supraorbital tubercles in a conspicuous row; middorsal portion of rostral partially sutured dorsomedially, bordered laterally by first supralabial on each side, dorsolaterally by prenasal on each side, and dorsally by internasal and two supranasals; internasal 1-3 (rarely absent); external nares bordered by 5-7 nasals (prenasal, anterior and posterior supranasals, 2 slightly enlarged postnasal, and 1 or 2 granular scales); preorbital scales 14-20; supralabials 9-12, grading into granular scales posteriorly; infralabials 9-12; eyes large, pupils vertical; eyelid fringe scales 51-59, those of upper eyelid slightly enlarged; outer surface of upper eyelid composed of granular scales of about one half the size of those on top of head, without enlarged tubercles; fold of skin originating from suborbital region extends posteroventrally across angle of jaw; external auditory meatus elliptical with long axis directed dorsoventrally; tympanum deeply recessed; mental triangular, bordered laterally by first infralabial on each side and posteriorly by 2-4 postmentals; postmentals bordered by 7-10 gular scales; gular region below lower jaws with enlarged tubercles; gular scales juxtaposed and granular, grading posteriorly into flat hexagonal pectoral scales and even larger ventral scales.

Neck narrower than body, covered with uniform granular scales interspersed with several sharply pointed conical tubercles on nape; tubercles on flanks conical, those of vertebral region somewhat flatter; dorsal body tubercles surrounded by 11-13 granular scales; dorsal tubercle rows at midbody 19-24; paravertebral tubercles between limb insertions 31-37, distinct vertebral row of tubercles absent; scales around midbody 118-130; ventral scales large; males with 25-30 precloacal pores in continuous series, females without precloacal pores (but pitted scales present); region posterior to vent covered by flat juxtaposed scales and greatly swollen, containing 1 or 2 enlarged tubercles on each side at level of vent; tail thick at base; light band on tail base in width of 9-12 granular scales and with 8-10 tubercles in transversal series.

Limbs relatively long and thin, covered dorsally with granular scales interspersed with several tubercles and ventrally with flat juxtaposed to subimbricate scales; dorsal granular scales grade into slightly flattened subimbricate scales on top of pes and manus; hind limbs larger than forelimbs; axillary pockets deep; subdigital lamellae wide, 10 or 11 under first finger, 18-21 under fourth finger, 11 or 12 under first toe, 21-25 under fourth toe; digits laterally compressed, increasing in length from first to fourth, fifth shorter than fourth (modified after Orlov et al. 2008; Nguyen 2011).

\section{Coloration in life (Fig. 3)}

Dorsal ground color of head, body and limbs signal brown (juveniles), grey-brown (young adults, SVL: 97.2-116 mm) and signal brown (adults), without small dark brown blotches (dark blotches present only on lower zone of flanks); dull white tubercles on dorsal body, limbs in juveniles, few orange tubercles on limbs in adults; iris orange or red brown; five bands on the dorsal ground, thin, immaculate without dark spots, slight bisque in juveniles, orange brown or yellow in adults, all edged anteriorly and posteriorly by thin dark brown bands, including one thin nuchal loop extending from posterior corners of eyes and posteriorly protracted (in V-shape), three body bands between limb insertions, and another one on tail base; ground color of tail dark brown, and signal brown at mottled tail base; 3-6 immaculate white caudal bands; ventral surfaces of head, body and limbs dull white and immaculate except for few dark brown spots on margin regions of gular and limbs. 
Goniurosaurus luii Grismer, Viets \& Boyle, 1999

Fig. 4

\section{Diagnosis}

Body splayed and gracile, SVL $86.5-126.5 \mathrm{~mm}$; external nares bordered by $5-8$ nasal scales; supraorbital region with a row of enlarged tubercles; outer surface of upper eyelid composed of granular scales, about one half the size of those on top of head and without enlarged tubercles; internasals 1 or 2 ; supralabials 8-12; infralabials 8-11; preorbital scales 13-16; eyelid fringe scales 46-61; postmentals 2-6; gular region below lower jaws with enlarged tubercles; paravertebral tubercles 29-38; scale rows around midbody 119-144, granular scales surrounding tubercles 9-14; axillary pockets deep; subdigital lamellae under fourth toe 20-26; precloacal pores in males 23-32; iris brown or bright orange; dorsal ground color of head, body and limbs pale brown to grey brown, mottled with small dark brown blotched; nuchal loop thin, posteriorly protracted (in V-shape); dorsal body bands between limb insertions 3, thin, immaculate yellow; gular region, belly, and ventral surface of limbs with brown spots (Grismer et al. 1999; Vu et al. 2006; Nguyen 2011).

\section{Description (Supp. file 1: Table S2)}

Body splayed and gracile, males: SVL 88.8-123.0 mm (mean \pm SE: $109.3 \pm 1.4 \mathrm{~mm}, \mathrm{n}=34$ ), TaL 2.8-96.8 mm (72.5 $\pm 3.8 \mathrm{~mm})$; adult females: SVL $86.5-126.5 \mathrm{~mm}(112.4 \pm 1.3 \mathrm{~mm}, \mathrm{n}=43), \mathrm{TaL}$ 43.3-102.2 mm (72.2 $\pm 2.1 \mathrm{~mm})$; juveniles: SVL 55.0-84.8 mm $(74.8 \pm 3.1 \mathrm{~mm}, \mathrm{n}=11)$, TaL 44.2$68.9(58.7 \pm 2.7 \mathrm{~mm})$ (Supp. file 1: Table S2); head triangular, wider than neck, covered by uniform granular scales interspersed with tubercles in temporal and occipital regions; scales on rostrum slightly larger and flatter; enlarged supraorbital tubercles in a conspicuous row; middorsal portion of rostral partially sutured dorsomedially, bordered laterally by first supralabial on each side, dorsolaterally by prenasal on each side, and dorsally by 1 or 2 internasal and two supranasals; internasals 1 or 2; external nares bordered by 5-8 nasal scales (prenasal, anterior and posterior supranasals, 2 slightly enlarged postnasal, and 1-3 granular scales); preorbital scales 13-16; supralabials 8-12, grading into granular scales posteriorly; infralabials 8-11; eyes large, pupils vertical; eyelid fringe scales 46-56, those of upper eyelid slightly enlarged; outer surface of upper eyelid composed of granular scales, about one half the size of those on top of head and without enlarged tubercles; fold of skin originating in suborbital region extends posteroventrally across angle of jaw; external auditory meatus elliptical with long axis directed dorsoventrally; tympanum deeply recessed; mental triangular, bordered laterally by first infralabial on each side and posteriorly by $2-6$ postmentals; postmentals bordered by $6-11$ gular scales; gular region below lower jaws with enlarged tubercles; gular scales juxtaposed and granular, abruptly grading posteriorly into flat hexagonal pectoral scales and even larger ventral scales.

Neck narrower than body, covered with uniform granular scales interspersed with several sharply pointed conical tubercles on nape; tubercles on flanks conical, those of vertebral region somewhat more flat; dorsal body tubercles surrounded by 11-13 granular scales; dorsal tubercle rows at midbody 20-24; paravertebral tubercles between limb insertions 29-38, distinct vertebral row of tubercles absent; scale rows around midbody 119-144; ventral scales large; males with 24-32 precloacal pores in a transverse continuous series, females without precloacal pores (but pitted scales present); region posterior to vent covered by flat juxtaposed scales and greatly swollen, containing 1-3 enlarged tubercles on each side at level of vent; tail thick at base, light band on tail base in width of 9-13 granular scales with 9-10 tubercles in transversal series; ventral caudals of tail base larger than dorsal caudals.

Limbs relatively long and thin, covered dorsally with granular scales interspersed with several tubercles and ventrally with flat juxtaposed to subimbricate scales; dorsal granular scales grade into slightly flattened subimbricate scales on top of pes and manus; hind limbs larger than forelimbs; axillary pockets deep; subdigital lamellae wide, 9-12 under first finger, 17-22 under fourth finger, 10-12 under first toe, 


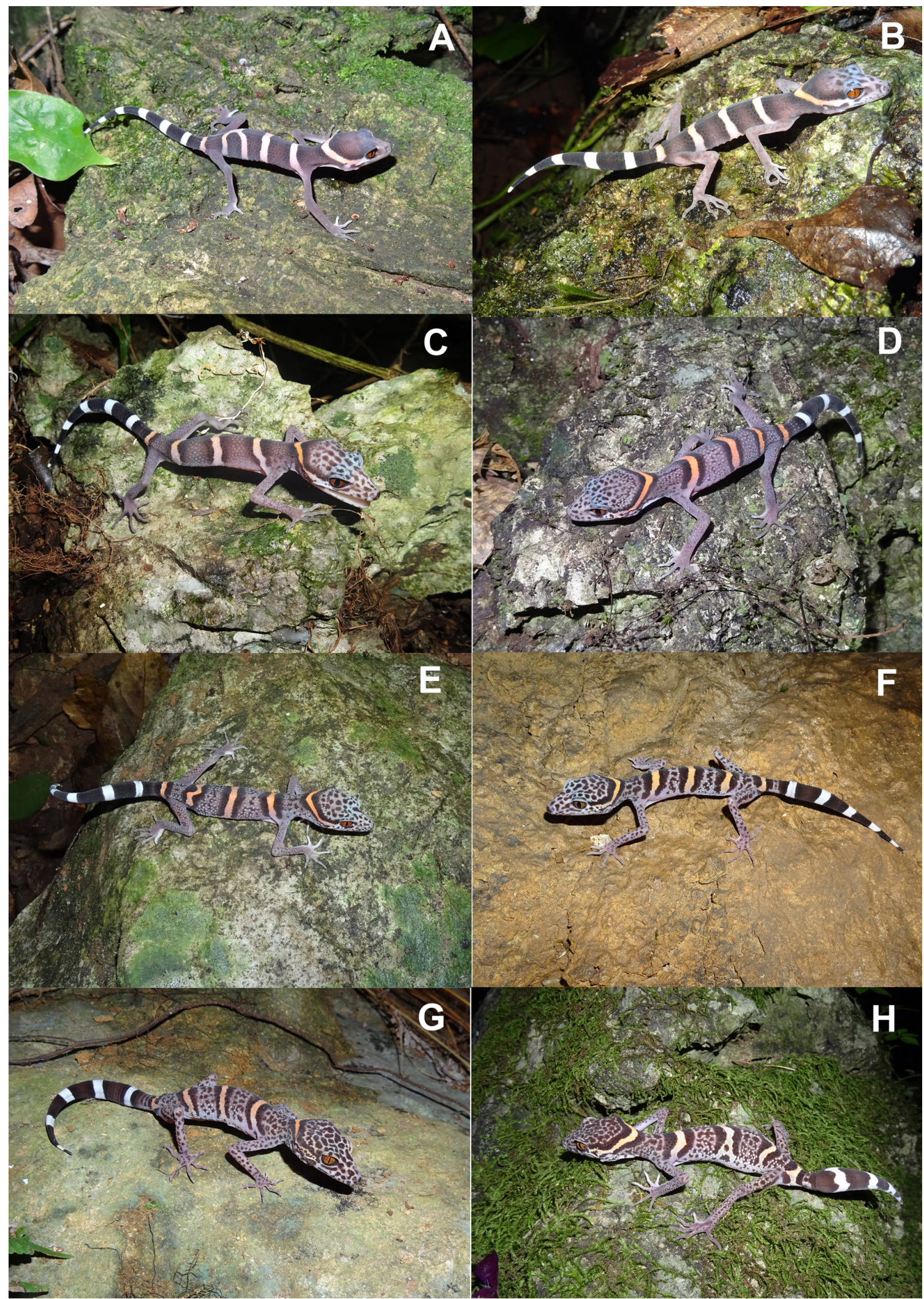

Fig. 4. Goniurosaurus luii Grismer, Viets \& Boyle, 1999. A. Juvenile ( $\mathrm{SVL}=61 \mathrm{~mm})$. B. Juvenile $(\mathrm{SVL}=70 \mathrm{~mm})$. C. Juvenile $(\mathrm{SVL}=80 \mathrm{~mm})$. D. Adult $(\mathrm{SVL}=89 \mathrm{~mm})$. E. Adult $(\mathrm{SVL}=96 \mathrm{~mm})$. F. Adult $(\mathrm{SVL} 70=104 \mathrm{~mm})$. G. Adult $(\mathrm{SVL}=116 \mathrm{~mm})$. H. Adult $(\mathrm{SVL}=126 \mathrm{~mm})$. 
20-26 under fourth toe; digits laterally compressed, increasing in length from first to fourth, fifth shorter than fourth (Grismer et al. 1999; Vu et al. 2006; Nguyen 2011).

\section{Coloration in life (Fig. 4)}

Dorsal ground color of head, body and limbs pale brown to grey brown, mottled with small dark brown circle blotches, juveniles without small dark brown blotches (except juveniles SVL $\geq 72 \mathrm{~mm}$ initially present on head); iris red brown or bright orange; five bands on dorsal ground, thin, immaculate without dark spots, slight bisque in juveniles, orange brown or yellow in adults, all edged anteriorly and posteriorly by thin dark brown bands, including one thin nuchal loop extending from posterior corners of eyes and posteriorly protracted (in V-shape), three body bands between limb insertions, and another one on tail base; ground color of tail nearly solid black, and grey brown at mottled tail base; 3-6 immaculate white caudal bands; ventral surfaces of head, body and limbs dull white with a few dark brown spots in gular region, on belly and limbs.

Goniurosaurus lichtenfelderi (Mocquard, 1897)

Fig. 5

\section{Diagnosis}

Body robust; SVL $80.6-113.5 \mathrm{~mm}$; external nares bordered by $5-10$ nasal scales; supraorbital region with a row of slightly enlarged tubercles; outer surface of upper eyelid composed of granular scales, about one-half the size of those on top of head and without enlarged tubercles; internasals 1-5 (rarely $1: 2 ; 2: 2$ or $2: 3$ ); supralabials $7-10$; infralabials $6-9$; preorbital scales $12-19$; eyelid fringe scales 43-58; postmentals 2-6; paravertebral tubercles 22-33; scale rows around midbody $117-131$, granular scales surrounding tubercles 10-13; axillary pockets shallow; subdigital lamellae under fourth toe 17-21; precloacal pores in males 25-33, in females 17-21; dorsal ground color of head, body and limbs dark purple-brown, without small dark brown blotches; transverse body bands 4, nuchal loop thin, posteriorly rounded, in U-shape; dorsal body bands between limb insertions 2, thin, light yellow; gular region and without dark spots; ventral surfaces of head, body and limbs dull white with a few dark dots on margin regions (modified after Grismer 2000; Grismer et al. 2002; Nguyen 2011).

Description (Supp. file 1: Table S2)

Body robust, adult males: SVL 80.6-113.5 mm (mean \pm SE: $97.8 \pm 0.7 \mathrm{~mm}, \mathrm{n}=92$ ), TaL $6.2-$ $84.8 \mathrm{~mm}(61.5 \pm 1.7 \mathrm{~mm})$; adult females: SVL 81.0-105.5 mm $(96.0 \pm 0.7 \mathrm{~mm}, \mathrm{n}=72)$, TaL 22.7$81.2 \mathrm{~mm}(58.4 \pm 1.4 \mathrm{~mm})$; juveniles: SVL 41.1-77.1 mm (65.4 $\pm 2.9 \mathrm{~mm}, \mathrm{n}=14)$, TaL 20.9-64.7 mm $(48.3 \pm 3.4 \mathrm{~mm}$ ) (Supp. file 1: Table S2); head triangular, wider than neck, covered by uniform granular scales interspersed with tubercles in temporal and occipital regions; scales on rostrum slightly larger and flatter; enlarged supraorbital tubercles in a conspicuous row; middorsal portion of rostral partially sutured dorsomedially, bordered laterally by first supralabial on each side, dorsolaterally by prenasal on each side, and dorsally by 1 or 2 internasals and two supranasals; internasals $1-5$ (rarely 1:2;2:2 or 2:3); external nares bordered by 5-10 nasals; preorbital scales $12-18$; supralabials $7-10$, grading into granular scales posteriorly; infralabials 6-9; eyes large, pupils vertical; eyelid fringe scales $47-58$, those of upper eyelid slightly enlarged; outer surface of upper eyelid composed of granular scales of about one-half the size of those on top of head, without enlarged tubercles; fold of skin originating in the suborbital region extends posteroventrally across angle of jaw; external auditory meatus elliptical; tympanum deeply recessed; mental triangular, bordered laterally by first infralabial on each side and posteriorly by $2-5$ postmentals; postmentals bordered by $7-10$ gular scales; gular region below lower jaws without enlarged tubercles; gular scales juxtaposed and granular, abruptly grading posteriorly into flat hexagonal scales and even larger ventral scales. 


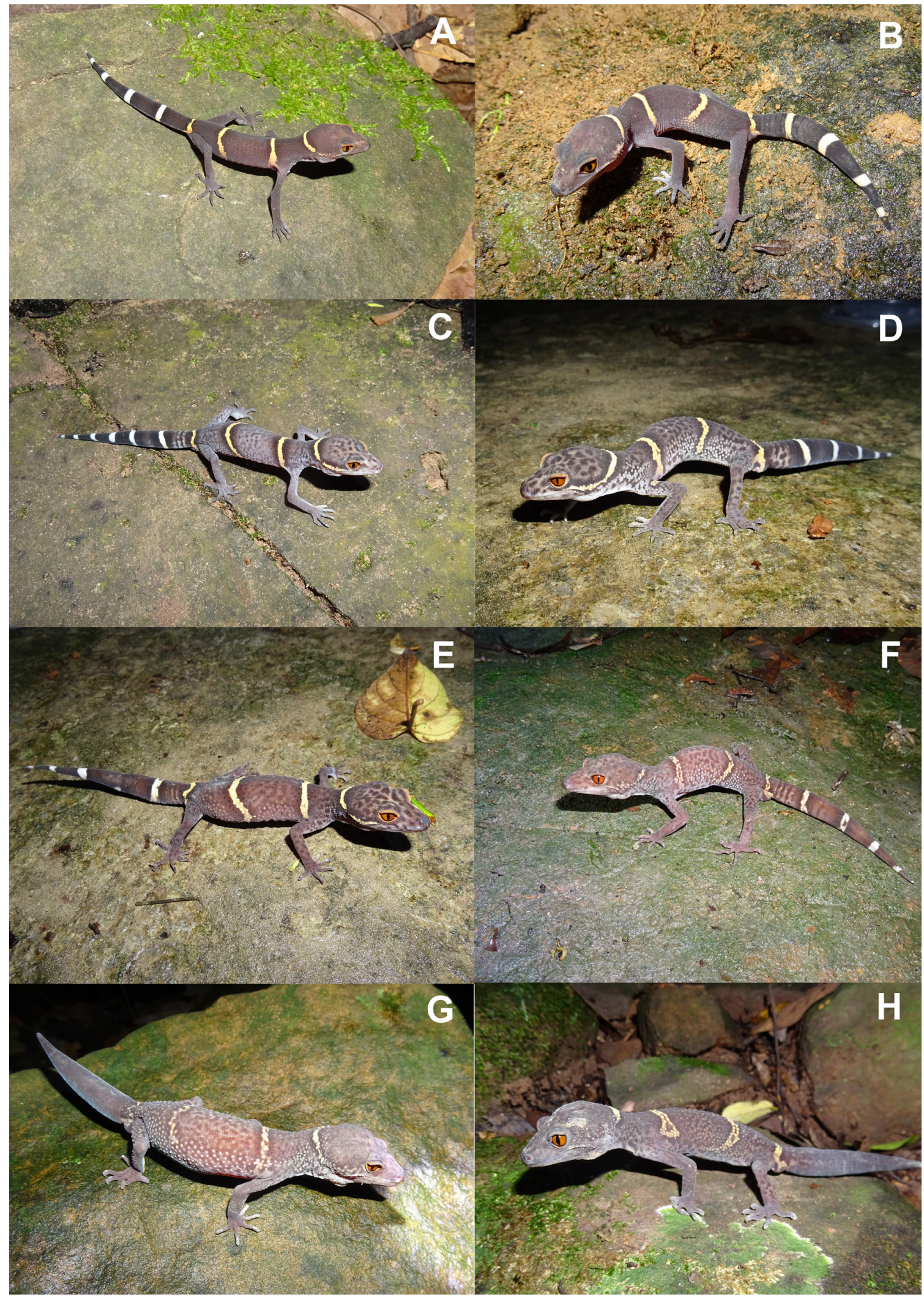

Fig. 5. Goniurosaurus lichtenfelderi (Mocquard, 1897). A. Juvenile ( $\mathrm{SVL}=55 \mathrm{~mm})$. B. Juvenile $(\mathrm{SVL}=63 \mathrm{~mm})$. C. Juvenile $(\mathrm{SVL}=72 \mathrm{~mm})$. D. Adult $(\mathrm{SVL}=80 \mathrm{~mm})$. E. Adult $(\mathrm{SVL}=91 \mathrm{~mm})$. F. Adult $(\mathrm{SVL}=97 \mathrm{~mm})$. G. Adult $(\mathrm{SVL}=105 \mathrm{~mm})$. H. Adult $(\mathrm{SVL}=113 \mathrm{~mm})$. 
Neck narrower than body, covered with uniform granular scales interspersed with several sharply conical tubercles on nape; tubercles on flanks conical, those of vertebral region somewhat more flat; dorsal body tubercles surrounded by 10-13 granular scales; dorsal tubercle rows at midbody 15-22; paravertebral tubercles between limb insertions 22-33, distinct vertebral row of tubercles absent; scales around midbody 117-130; ventral scales large; males with 24-33 precloacal pores in a transverse continuous series, females without distinct precloacal pores (but 25-33 pitted scales present); region posterior to vent covered by flat juxtaposed scales and greatly swollen, containing 1 (rarely 2 ) enlarged tubercles on each side at the level of vent; tail thick at base; light band on tail base in width of 4-7 scales and with 6-10 tubercles in a transversal series.

Limbs robust, covered dorsally with granular scales interspersed with several tubercles and ventrally with flat juxtaposed to subimbricate scales; dorsal granular scales grade into slightly flattened subimbricate scales on top of pes and manus; hind limbs larger than forelimbs; axillary pockets shallow; subdigital lamellae wide, 6-9 under first finger, 13-17 under fourth finger, 6-10 under first toe, 16-20 under fourth toe; digits laterally compressed, increasing in length from first to fourth, fifth shorter than fourth (modified after Grismer 2000; Grismer et al. 2002; Nguyen 2011).

\section{Coloration in life (Fig. 5)}

Dorsal ground color of head, body and limbs grey and grey brown in juveniles without blotches and chestnut brown in adults with dark brown blotches (in animals with SVL $>80 \mathrm{~mm}$ ); iris orange or redish brown; four bands on the dorsal ground, thin, yellow in both juveniles and adults, immaculate without dark spots (few dark brown spots present in some animals), all edged anteriorly and posteriorly by thin dark brown bands, including one thin nuchal loop extending from posterior corners of eyes and posteriorly rounded (in U-shape), two body bands between limb insertions, and another one on tail base; ground color of tail dark brown, and grey brown at mottled tail base; 3-5 immaculate white caudal bands except first band slightly yellow, and some animals with regenerated tail present immaculate grey brown without white caudal bands; ventral surfaces of head, body and limbs dull white with a few dark dots on margin regions of belly, limbs, gular region, but immaculate dull white in juveniles ( $\mathrm{SVL} \leq 65 \mathrm{~mm}$ ) without dark spots.

\section{Morphological comparisons}

Our morphological comparisons of the tiger gecko species (except for G. araneus) from Vietnam revealed an overall significant difference in the snout-vent length (SVL). As the result, G. huuliensis had the largest SVL, while G. lichtenfelderi had the shortest SVL in both adult males and females, compared to the other tiger geckos $(\mathrm{P}<0.05)$. However, the SVL of G. catbaensis was not significantly different from that of G. luii ( $\mathrm{P}>0.05$, Supp. file 2: Fig. S1).

The PCA of 18 selected morphometric characters estimated the first (PC1) and second principal (PC2) components to explain $82.5 \%$ ( $74.5 \%$ and $8.0 \%$, respectively) of the variance among the four investigated species of Goniurosaurus in Vietnam (Supp. file 2: Fig. S2). The extracted PC1 and PC2 scores of the PCA differ significantly among the four species (Kruskal-Wallis's test, $\mathrm{P}<0.05$ ), of which the values and morphometric spaces of G. lichtenfelderi are not concordant with the three remainders (Fig. S2). Three morphological factors, namely head length (HL), head width (HW), and mouth width (MW) highly account for the overall difference in the PC1 score, while the PC2 score is mainly explained by the body height (BH) and body width (BW) (Supp. file 2: Fig. S2).

Regarding the comparisons of the 17 species of Goniurosaurus from China and Vietnam, the multiple correspondence analysis (MCA) clustered them separately into three groups (G. lichtenfelderi group, G. luii group and G. yingdeensis group) represented with different meristic spaces on the spatial coordinate of Dim 1 and Dim 2 (Fig. 6A, Table 1). The characters of fourth toe (LT4), body limb shape 


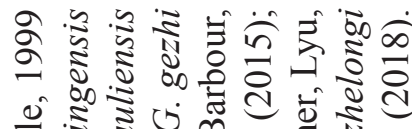

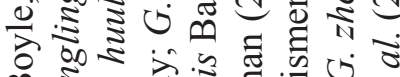

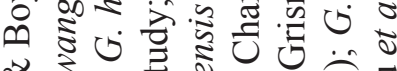

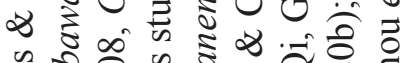

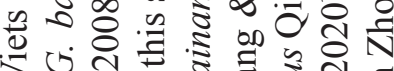

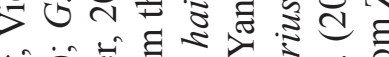

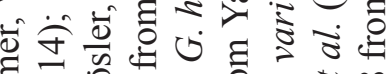

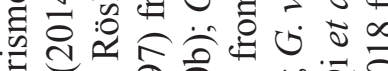

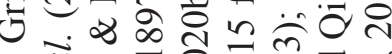
उٓ 施

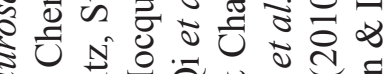

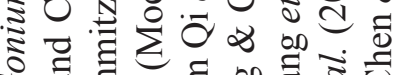

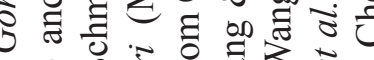

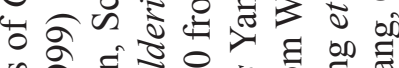

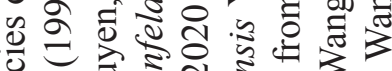

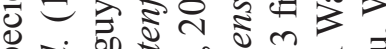
क्षें

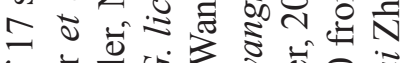

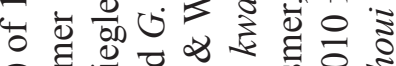

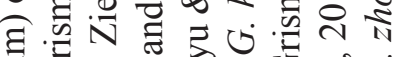

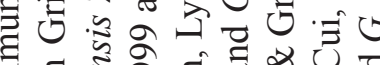

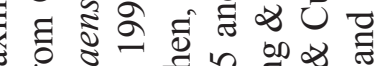

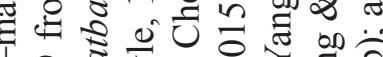
1 व ปे

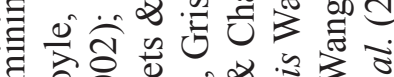

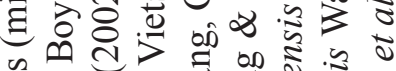

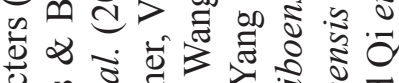

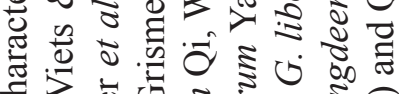

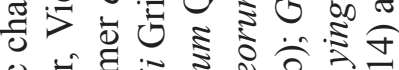

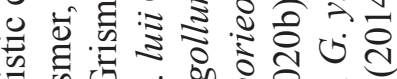

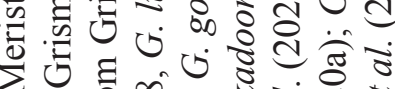
एँ

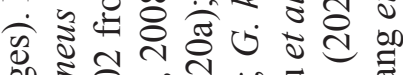

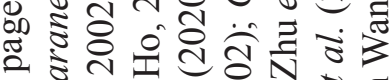

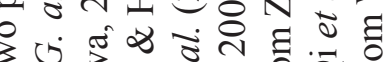

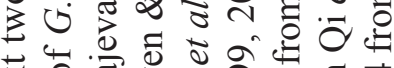
区

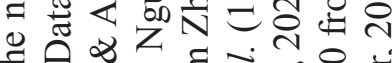
घ

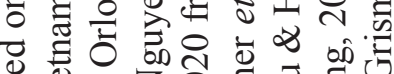

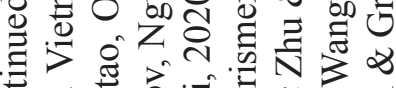

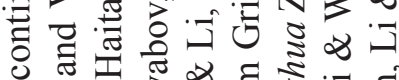

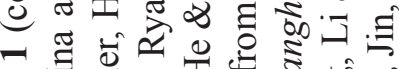

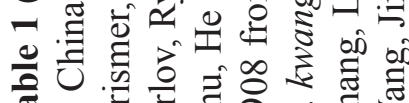

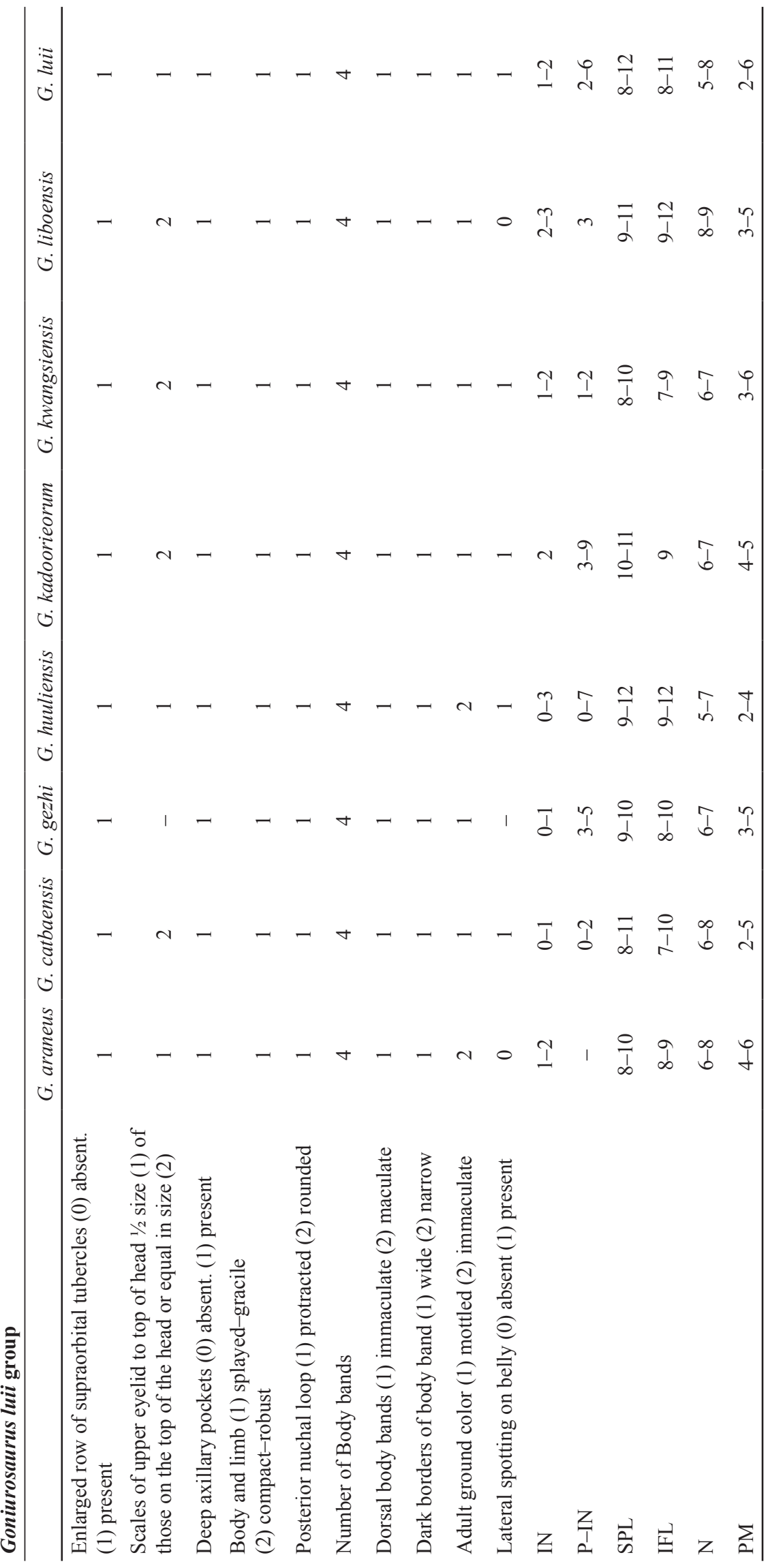




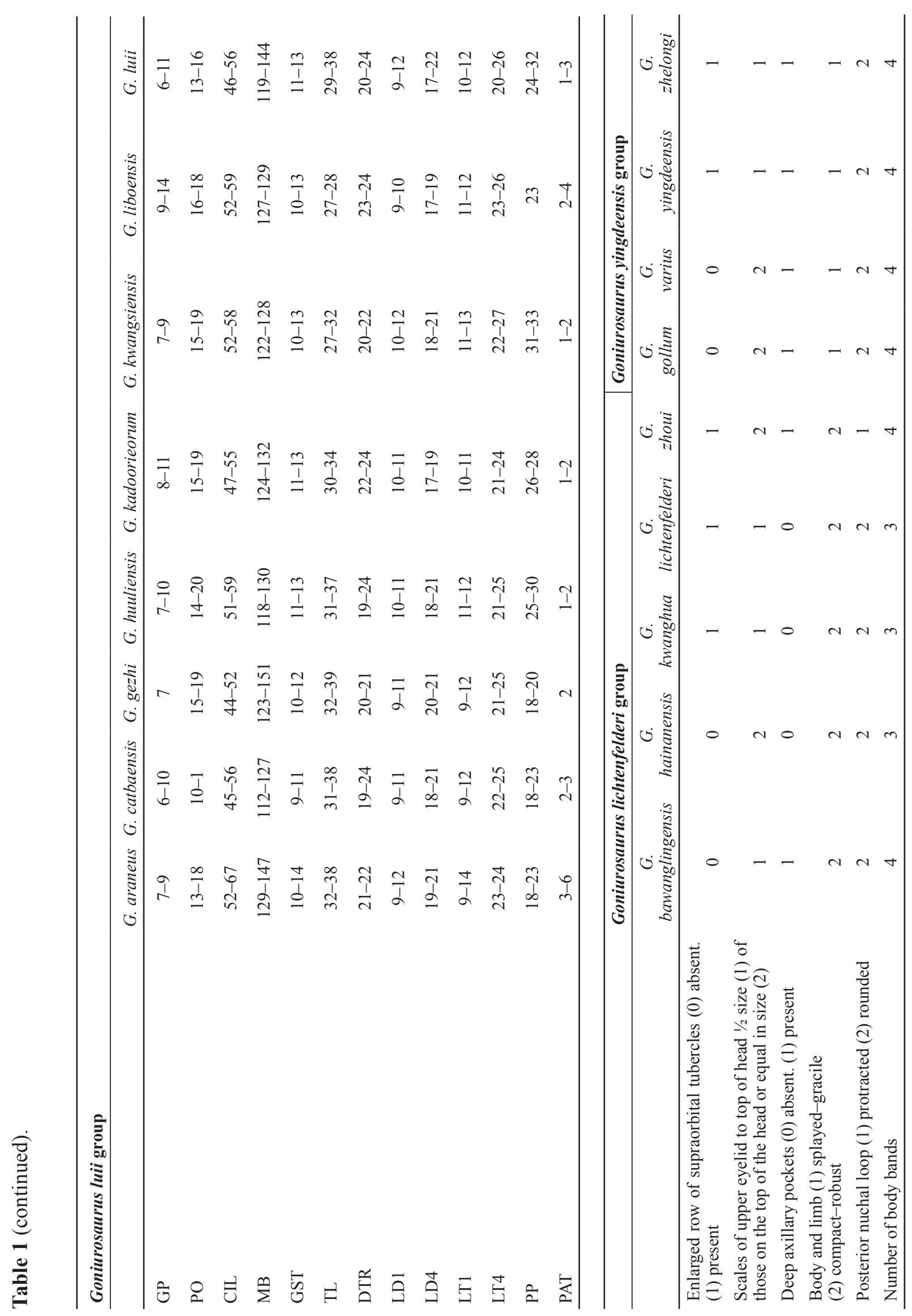




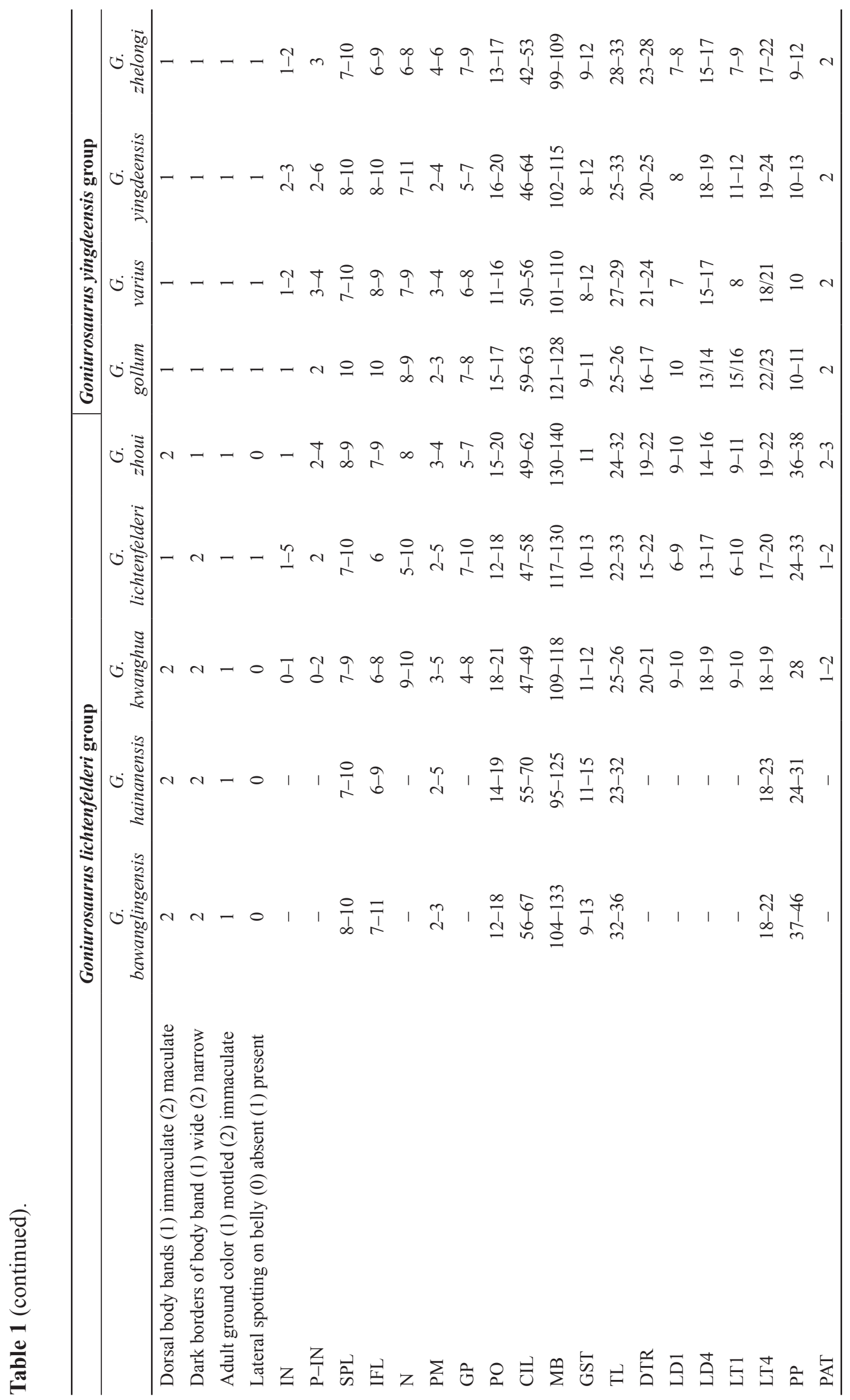



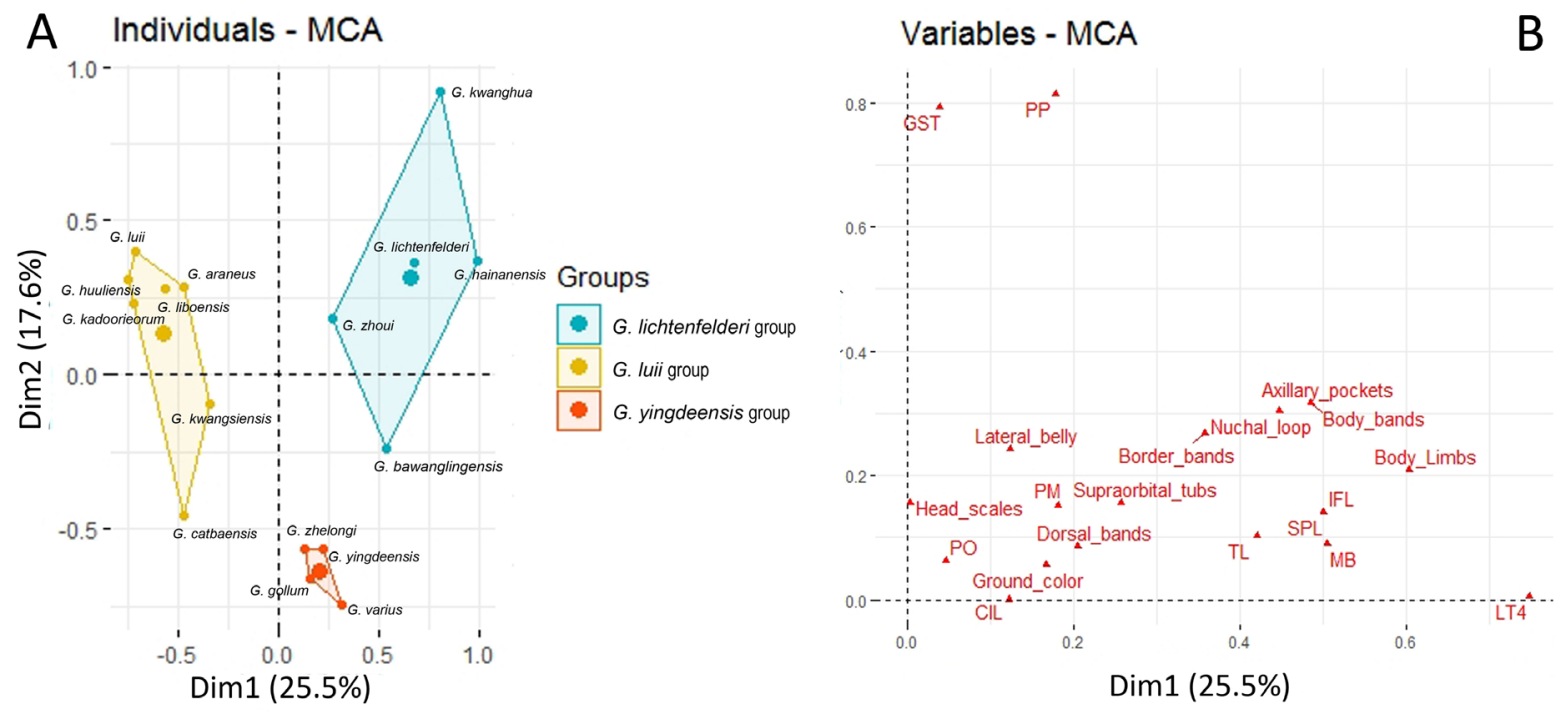

Fig. 6. A. Multiple correspondence analysis (MCA) on meristic variation among 17 recorded species of Goniurosaurus Grismer, Viets \& Boyle, 1999 in China and Vietnam. B. Correlation between meristic variables and principal dimensions (Dim1 and Dim2).

and body bands highly account for the Dim1 score, whereas the characters of precloacal pores (PP) and granular scales surrounding dorsal tubercles (GST) are the most correlated with the Dim 2 score (Fig. 6B).

\section{Key to the species of Goniurosaurus (Fig. 7, Table 1)}

Modified from Grismer et al. (1999, 2002), Vu et al. (2006), Orlov et al. (2008), Ziegler et al. (2008), Wang et al. (2010, 2013, 2014), Nguyen (2011), Chen et al. (2014), Yang \& Chan (2015), Honda \& Ota (2017), Zhou et al. (2018, 2020a, 2020b), Qi et al. (2020a, 2020b) and the present study.

1. Precloacal pores in males present, claws are sheathed by scales 7

- Precloacal pores absent, unsheathed claws (G. kuroiwae group)

2. Yellow brown to gold iris; a single scale at the base of each digit which is occasionally slightly enlarged

- Blood-red iris; one to three enlarged scales at the base of each digit on the limbs

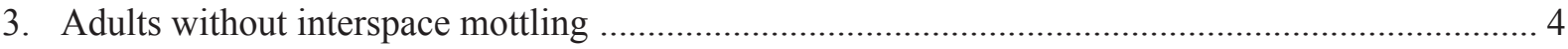

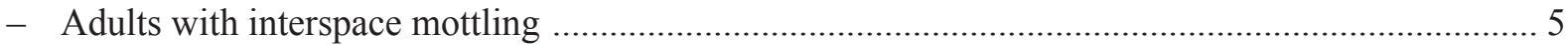

4. Robust body stature; dorsal body tubercles between the limb insertions in cross-section are triangular to elliptical and sharply keeled anteriorly; 34-42 paravertebral tubercles; ventral scales are juxtaposed and sharply raised

G. toyamai Grismer, Ota \& Tanaka, 1994

- Slender body stature; dorsal body tubercles between the limb insertions in cross-section are smooth or very weakly keeled; 22-29 paravertebral tubercles; ventrals are flat, wide, and subimbricate to imbricate G. splendens (Nakamura \& Uéno, 1959)

5. Dorsal banding absent or incomplete G. kuroiwae (Namiye, 1912)

- Prominent dorsal pattern consisting of transverse bands between the nape of the neck and the caudal constriction 
6. No such reddish or pinkish tint in dorsal pattern and iris G. orientalis (Maki, 1931)

- Reddish or pinkish tint to some extent in dorsal pattern and iris

7. Precloacal pores in males less than 16 (G. yingdeensis group) ……............................................. 8

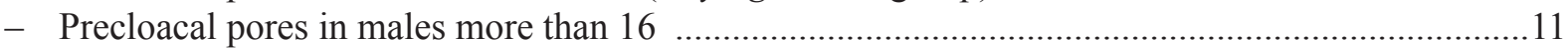

8. Scales around midbody $121-128$; longitudinal dorsal tubercle rows at midbody $16-17$

G. gollum Qi, Wang, Grismer, Chen, Lyu \& Wang, 2020

- Scales around midbody 99-115; longitudinal dorsal tubercle rows at midbody 20-28 ................. 9

9. Nuchal loop and body bands with small dark blotches; enlarged row of supraorbital tubercles absent; trunk of body usually with a longitudinal light vertebral stripe

G. varius Qi, Grismer, Lyu, Zhang, Li \& Wang, 2020

- Nuchal loop and body bands without dark blotches; enlarged row of supraorbital tubercles present; trunk of body without a longitudinal light vertebral stripe

10. Tubercles between orbits present; gular scales bordering the postmentals 2-4; preorbital scales 5-7

G. yingdeensis Wang, Yang \& Cui, 2010

- Tubercles between orbits absent; gular scales bordering the postmentals 4-6; preorbital scales 7-9

G. zhelongi Wang, Jin, Li \& Grismer, 2014

11. Body and limbs robust (G. lichtenfelderi group)

- Body and limbs splayed gracile (G. luii group)

12. Precloacal pores in males 37-46 ....... G. bawanglingensis Grismer, Haitao, Orlov \& Anajeva, 2002

- Precloacal pores in males fewer than 37

13. Nuchal loop protracted posteriorly (in V-shape); number of body bands 4; axillary pockets deep; precloacal pores in males more than 33

G. zhoui Zhou, Wang, Chen \& Liang, 2018

- Nuchal loop rounded posteriorly (in U-shape); number of body bands 3; axillary pockets shallow; precloacal pores in males fewer than 33

14. Eyelid fringe scales 55-70; enlarged row of supraorbital tubercles absent; scales of upper eyelid to top of head equal of those on the top of the head in size

G. hainanensis Barbour, 1908

- Eyelid fringe scales 47-58; enlarged row of supraorbital tubercles present; scales of upper eyelid to top of head $1 / 2$ of those on the top of the head in size

15. Lateral spotting on belly absent; preorbital scales 18-21; scales around midbody 109-118; subdigital lamellae under the fourth finger 18-19

G. kwanghua Zhu \& He, 2020

- Lateral spotting on belly present; preorbital scales 12-18; scales around midbody 117-130; subdigital lamellae under the fourth finger 13-17

G. lichtenfelderi (Mocquard, 1897)

16. Internasal absent G. catbaensis Ziegler, Nguyen, Schmitz, Stenke \& Rösler, 2008

- Internasal present

17. Postcloacal tubercles 3-6

G. araneus Grismer, Viets \& Boyle, 1999

- Postcloacal tubercles 1-3

18. Adult body length $(\mathrm{SVL})>126 \mathrm{~mm}$; dorsum without dark blotches

G. huuliensis Orlov, Ryabov, Nguyen, Nguyen \& Ho, 2008

- Maximum body length $(\mathrm{SVL}) \leq 126 \mathrm{~mm}$; dorsum with dark blotches 
19. Dorsum with many small dark blotches

- Dorsum with rarely scattered dark blotches

20. Outer surface of upper eyelid composed of granular scales, about the same size of those on top of head and with enlarged tubercles

G. gezhi Zhu, He \& Li, 2020

- Enlarged row of supraorbital tubercles present; scales of upper eyelid to top of head $1 / 2$ of those on the top of the head in size

21. Precloacal pores in males 31-33

G. kwangsiensis Yang \& Chan, 2015

- Precloacal pores in males fewer than 31

22. Lateral spotting on belly present; nasal scales 6-7; paravertebral tubercles between limb insertions 30-34; precloacal pores $26-28$ G. kadoorieorum Yang \& Chan, 2015

- Lateral spotting on belly absent, nasal scales 8-9; paravertebral tubercles between limb insertions $27-28$; precloacal pores 23 G. liboensis Wang, Yang \& Grismer, 2013

\section{Discussion}

\section{Taxonomic review}

Our phylogenetic analyses strongly suggest that populations recorded from Vietnam indeed belong to four known species, namely G. catbaensis, G. huuliensis, G. lichtenfelderi and G. luii (Grismer et al. 1999; Vu et al. 2006; Orlov et al. 2008; Ziegler et al. 2008; Nguyen et al. 2009; Nguyen 2011). Despite extensive surveys over the last two decades, G. araneus has not been recorded in Vietnam, leaving its accurate type locality in Cao Bang Province, northern Vietnam ambiguous (Grismer et al. 1999; Ngo et al. 2016). It is possible that the species has been extirpated from Vietnam as a result of overexploitation to supply the international pet trade or that the species has never occurred at the documented type locality (Grismer et al. 1999; Ngo et al. 2016). Similarly, G. luii has not been recorded again at its type locality in China (Grismer et al. 1999; Stuart et al. 2006; Yang \& Chan 2015).

Molecular results supported by our study confirm that G. murphyi, described by Orlov \& Darevsky (1999), is a junior synonym of $G$. lichtenfelderi (Grismer 2000). All mainland populations of G. lichtenfelderi found in granitic forests are conspecific with those from the granitic offshore islands in Bai Tu Long National Park, Quang Ninh Province, northern Vietnam (type locality), with an intraspecific genetic distance of less than $0.7 \%$ (Supp. file 1: Table S1). However, a few issues need to be resolved in the future. In particular, G. hainanensis was recovered as polyphyletic by Liang et al. (2018) and our phylogenetic analyses. Moreover, Zhu et al. (2020a) suggested that G. luii and G. kadoorieorum are polyphyletic. We highly recommend that they may be synonymized. Samples assigned to G. kuroiwae were not recovered as monophyletic in our phylogenetic analysis. It is possible that more cryptic species from the Japanese group will be discovered. Further studies with additional samples, especially from type localities, should be undertaken to clarify these taxonomic problems.

Regarding morphological analyses, six morphometric characters, namely snout-vent length, head length, head width, mouth width, body height and body width strongly supported the overall difference among the four species in Vietnam and five characteristics, namely fourth toe, body and limb shapes, body bands, precloacal pores and granular scales surrounding dorsal tubercles, mainly accounted for the variation among the 17 tiger geckos from China and Vietnam. Six species of the G. kuroiwae group from Japan were not included in this study. However, the Japanese G. kuroiwae group can be distinguished from Chinese and Vietnamese species by the absence of precloacal pores and unsheathed claws (Wang et al. 2014; Yang \& Chan 2015; Honda \& Ota 2017). We highly recommend that all these traits be considered as diagnostic characters for species of Goniurosaurus. 

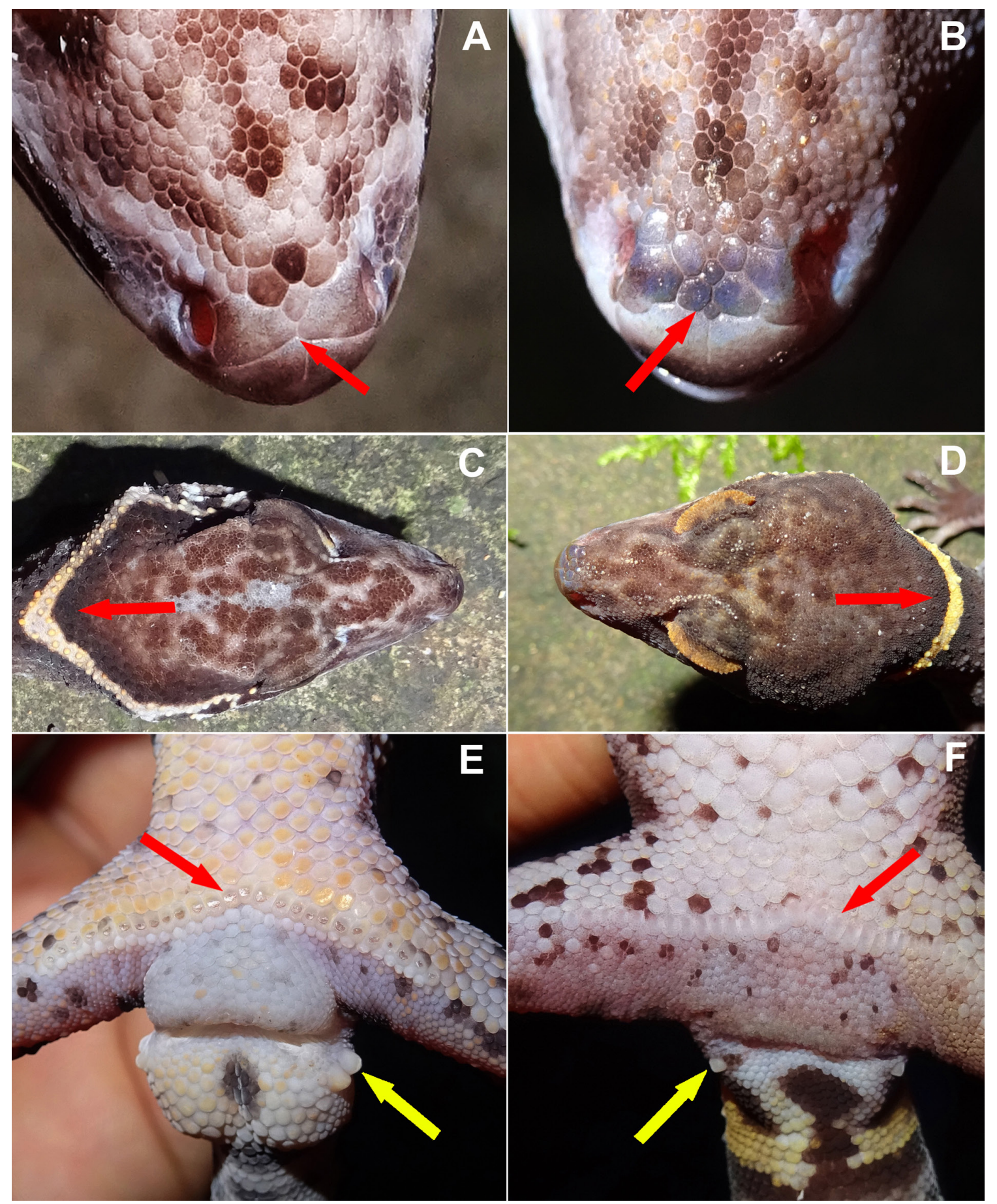

Fig. 7. A few key characters for species identification in the genus Goniurosaurus Grismer, Viets \& Boyle, 1999. A. Snout tip of G. catbaensis Ziegler, Nguyen, Schmitz, Stenke \& Rösler, 2008 with lacking postrostral (internasal) and two supranasals are in contact with each other. B. Snout tip of G. lichtenfelderi (Mocquard, 1897) with few internasals. C. Nuchal loop of G. huuliensis Orlov, Ryabov, Nguyen, Nguyen \& Ho, 2008 protracted posteriorly (in V-shape). D. Nuchal loop of G. lichtenfelderi rounded posteriorly (in U-shape). E. Precloacal pores and large swollen hemipenial bulges of G. luii Grismer, Viets \& Boyle, 1999 in males, and two postcloacal tubercles. F. Indistinct precloacal pores of $G$. lichtenfelderi in females and only one postcloacal tubercle on each site. Yellow arrows point to postcloacal tubercles, and red arrows to other scales. 
Based on our identification key in accordance with the morphological and phylogenetic analyses, all tiger gecko species were grouped into four separate species groups, in agreement with the previous findings (Liang et al. 2018; Qi et al. 2020a, 2020b; Zhu et al. 2020a, 2020b). Liang et al. (2018), Qi et al. (2020a, $2020 \mathrm{~b}$ ) and our genetic analyses revealed that G. bawanglingensis and G. zhoui are embedded within the G. lichtenfelderi group, while they were previously placed as sister taxa in the G. luii group due to superficial morphological similarities as a result of adaptation to karst habitat (Grismer et al. 2002; Zhou et al. 2018). In accordance with these genetic findings, we found that the two karst-adapted species are morphologically most similar to three remaining granite-stream-adapted species of the G. lichtenfelderi group. Further comparative studies in southern China and Japan may help to resolve the phylogenetic relations of the genus Goniurosaurus.

Due to the high degrees of adaptation to specific microhabitats and local endemism, the genus Goniurosaurus could serve as a model system to study the evolution in lizards. In Vietnam, all species of Goniurosaurus have been found in isolated geographic ranges and none of them occurs in sympatry. For example, the distribution of G. luii stretches to the north of the Lang Son and Cao Bang provinces (Ngo et al. 2016), while G. huuliensis has been recorded in karst forests in the south of Lang Son Province. Goniurosaurus catbaensis is currently known only from offshore islands in Cat Ba National Park and the Ha Long Bay. Goniurosaurus lichtenfelderi can only be found in granitic habitats at several mainland localities and on some offshore islands in the Bai Tu Long Archipelago, which is contiguous with Ha Long Bay in the Gulf of Tonkin (Orlov et al. 2008; Gawor et al. 2016; Ngo et al. 2019a). Goniurosaurus araneus has not yet been re-discovered at its type locality in Cao Bang Province, and we only recorded G. luii inhabiting limestone karst forests of Cao Bang Province (Grismer et al. 1999; Vu et al. 2006; Ngo et al. 2016). The allopatric distribution has also been documented among species of Goniurosaurus from China. To date, neither the four species from the Hainan Archipelago, nor the five species of the G. luii group from Guangxi Province, China, nor the four known species of the G. yingdeensis group from Guangdong Province were recorded to occur in sympatry (Grismer et al. 2002; Zhou et al. 2018; Zhu et al. 2020a, 2020b). A large river (Zuojiang River) is regarded as the potential geographic barrier between the two species G. luii and G. araneus within Nonggang Nature Reserve, China (Chen et al. 2014). Likewise, geographic barriers (e.g., rivers and canyons) are considered to prevent a genetic exchange between members of the G. yingdeensis group (Qi et al. 2020a). The global rising of the sea level during the last melting period of glacial ice has shaped the myriad of archipelagoes (Clements et al. 2006; Ziegler et al. 2008; Liang et al. 2018; Ngo et al. 2019a). Thus, the oceanic barrier known as an important geographic feature has constrained current distributions and limits the genetic exchange of insular tiger gecko species, such as G. catbaensis, species from the Hainan Archipelago and G. kuroiwae group (Ziegler et al. 2008; Honda \& Ota 2017; Liang et al. 2018; Zhu et al. 2020b). However, the last glacial maximum period occurring around 10000-50000 years ago was not sufficiently long for speciation events within Goniurosaurus (Clements et al. 2006; Sterling et al. 2006; Ziegler et al. 2008). Indeed, by employing a molecular dating method, Liang et al. (2018) estimated that the latest speciation events among tiger geckos took place approximately 2.8-2.9 $\mathrm{Ma}$, in the late Pliocene, between G. yamashinae-G. orientalis, and G. huuliensis-G. luii. It is likely that the global warming during the Pliocene promoted the diversification in the genus, as also reported in the crocodile newts (genus Tylototriton Anderson, 1871) in Asia (Bernardes et al. 2020). Thus, the genus Goniurosaurus might offer a unique opportunity to investigate mechanisms of speciation and evolutionary adaptation, that are expected to highly correlate with a pre-dominantly allopatric mode of diversification.

\section{Implications for conservation}

The taxonomy of several existing species complexes requires further investigation and new species are still being discovered. Nevertheless, wild populations of the genus Goniurosaurus are under high risks of extinction, due to habitat destruction and exploitation for national and international trade. Of 
the 23 described tiger gecko species, 12 have been considered threatened (listed as VU, EN and CR) and one data deficient (DD) in the IUCN Red List (Ngo et al. 2019b). Assessments for the remaining species are still lacking. In order to better regulate the international trade in the species, all species of Goniurosaurus from China and Vietnam were recently listed in CITES Appendix II and the Vietnamese species were also protected under the Governmental Decree 06/2019/ND-CP (Group IIB). Trade data in the US showed that about half of the number of traded tiger geckos were only assigned to the genus level (Ngo et al. 2019b). This fact could be a consequence of the highly similar morphology among tiger gecko species and lacking guidance to distinguish the species (Ngo et al. 2019b). Besides, the conservation status and national protection status are not assessed equally among species. Therefore, the present identification guide will aid to prevent tiger geckos from being traded under a wrong name to circumvent legislations. The detailed descriptions of morphology provided in this study can assist local, national, and international authorities, such as local rangers, CITES authorities, custom officers, in enforcing international regulations. The identification key can also be useful for scientists and breeders to accurately identify tiger gecko species. However, morphological identification of captive lineages should be treated with reservation, as some breeders have produced hybrids (L. Grismer, pers. comm.), and thus molecular identification tools should be consulted as well in these cases.

After the CITES listing, four new species, namely G. gezhi, G. gollum, G. kwanghua and G. varius were recently described from China, which are automatically listed in Appendix II of the Convention (Qi et al. 2020a, 2020b; Zhu et al. 2020a, 2020b). As the Japanese species appear to be similarly threatened and to prevent a shift towards international trade, Janssen \& Shepherd (2019) and Ngo et al. (2019b) highly recommended that the Japanese species be also included in the CITES Appendices. During the time of writing, the Japanese Ministry for Environment announced to list all six endemic species of Goniurosaurus from Japan in CITES Appendix III to prevent over-harvesting of wild animals for trafficking activities. As a result, the listing of all Japanese species in Appendix III has come into force since 14 February 2021 (CITES Notification No. 2020/068).

\section{Acknowledgments}

For supporting fieldwork and issuing relevant permits, we thank the authorities of the Cat Ba National Park (CBNP), Hai Phong City, Huu Lien Nature Reserve, Lang Son Province, Bai Tu Long National Park, Quang Ninh Province, Tay Yen Tu Nature Reserve, Bac Giang Province, Yen Tu Nature Reserve and the Management Department of Ha Long Bay, Quang Ninh Province. We are thankful to K.X. Nguyen (CBNP), M.L. Pham (MDHLB), N.H. Nguyen, C.T. Pham, T.Q. Phan (IEBR, Ha Noi), L.T. Pham (Thai Nguyen University), D.T. Le, H. Tran (Ha Noi National University of Education), for assistance in the field. We are grateful to T. Pagel and C. Landsberg (Cologne Zoo), S.V. Nguyen, (IEBR, Hanoi), L.V. $\mathrm{Vu}$ and T.T. Nguyen (VNMN, Hanoi) for their support of conservation-based biodiversity research in Vietnam. This research was supported by the Vietnam Academy of Science and Technology (Project Code KHCBSS.02/20-22) and the Ministry of Science and Technology's Program 562 (grant no. ĐTĐL. CN-64/19). Field surveys were partially funded by Cologne Zoo, the Wildlife Conservation Society ('WCS') John Thorbjarnarson Fellowship for Reptile Research Grant, the Mohamed bin Zayed Species Conservation fund (Project: 170515492) to H.N. Ngo. Field equipment was supported by the Idea Wild. Cologne Zoo is partner of the World Association of Zoos and Aquariums (WAZA): Conservation Project 07011, 07012 (Herpetodiversity Research, Amphibian and Reptilian Breeding and Rescue Stations). Research of Hai Ngoc Ngo in Germany is funded by the German Academic Exchange Service (DAAD).

\section{References}

Bernardes M., Le M.D., Nguyen T.Q., Pham C.T., Pham A.V., Nguyen T.T., Rödder D., Bonkowski M. \& Ziegler T. 2020. Integrative taxonomy reveals three new taxa within the Tylototriton asperrimus complex (Caudata, Salamandridae) from Vietnam. ZooKeys 935: 121-164.

https://doi.org/10.3897/zookeys.935.37138 
Chen T.B., Meng Y.J., Jiang K., Li P.P., Wen B.H., Lu W., Lazell J. \& Hou M. 2014. New record of the leopard gecko Goniurosaurus araneus (Squamata: Eublepharidae) for China and habitat portioning between geographically and phylogenetically close leopard geckos. IRCF Reptiles \& Amphibians 21 (1): $16-27$.

Clements R., Sodhi N.S., Schilthuizen M. \& Ng P.K.L. 2006. Limestone karsts of Southeast Asia: imperiled arks of biodiversity. BioScience 56: 733-742.

https://doi.org/10.1641/0006-3568(2006)56[733:LKOSAI]2.0.CO;2

CITES. 2019. E CoP18 Proposal Number 27. Available from https://cites.org/sites/default/files/eng/cop/18/prop/19032019/E-CoP18-Prop-27.pdf [accessed 25 Apr. 2021].

Gawor A., Pham T.C., Nguyen Q.T., Nguyen T.T., Schmitz A. \& Ziegler T. 2016. The herpetofauna of the Bai Tu Long National Park, northeastern Vietnam. Salamandra 52 (1): 23-41.

Gomes V., Carretero M.A. \& Kaliontzopoulou A. 2016. The relevance of morphology for habitat use and locomotion in two species of wall lizards. Acta Oecologica 70: 87-95.

https://doi.org/10.1016/j.actao.2015.12.005

Grismer L.L. 2000. Goniurosaurus murphyi Orlov and Darevsky: a junior synonym of Goniurosaurus lichtenfelderi Mocquard. Journal of Herpetology 34 (3): 486-488. https://doi.org/10.2307/1565379

Grismer L.L., Viets B.E. \& Boyle L.J. 1999. Two new continental species of Goniurosaurus (Squamata: Eublepharidae) with a phylogeny and evolutionary classification of the genus. Journal of Herpetology 33 (3): 382-393. https://doi.org/10.2307/1565635

Grismer L.L., Shi H.T., Orlov N.L. \& Ananjeva N.B. 2002. A new species of Goniurosaurus (Squamata: Eublepharidae) from Hainan Island, China. Journal of Herpetology 36: 217-224.

https://doi.org/10.2307/1565994

Hillis D.M. \& Bull J.J. 1993. An empirical test of bootstrapping as a method for assessing confidence in phylogenetic analysis. Systematic Biology 42: 182-192. https://doi.org/10.1093/sysbio/42.2.182

Honda M. \& Ota H. 2017. On the live coloration and partial mitochondrial DNA sequences in the topotypic population of Goniurosaurus kuroiwae orientalis (Squamata: Eublepharidae), with description of a new subspecies from Tokashikijima Island, Ryukyu Archipelago, Japan. Asian Herpetological Research 8: 96-107. https://doi.org/10.16373/j.cnki.ahr.170003

Honda M., Kurita T., Toda M. \& Ota H. 2014. Phylogenetic relationships, genetic divergence, historical biogeography and conservation of an endangered gecko, Goniurosaurus kuroiwae (Squamata: Eublepharidae), from the Central Ryukyus, Japan. Zoological Science 31: 309-320.

https://doi.org/10.2108/zs130201

Janssen J. \& Shepherd C.R. 2019. Trade in endangered and critically endangered Japanese herpetofauna endemic to the Nansei Islands warrants increased protection. Current Herpetology 38 (1): 99-109. https://doi.org/10.5358/hsj.38.99

Kassambara A. 2017. Practical Guide to Principal Component Methods in R: PCA, M(CA), FAMD, $M F A, H C P C$, factoextra. Multivariate Analysis II, STHDA.com.

Le M., Raxworthy C.J., McCord W.P. \& Mertz L. 2006. A molecular phylogeny of tortoises (Testudines: Testudinidae) based on mitochondrial and nuclear genes. Molecular Phylogenetics and Evolution 40: 517-531. https://doi.org/10.1016/j.ympev.2006.03.003

Liang B., Zhou R.B., Liu Y.L., Chen B., Grismer L.L. \& Wang N. 2018. Renewed classification within Goniurosaurus (Squamata: Eublepharidae) uncovers the dual roles of a continental island (Hainan) in species evolution. Molecular Phylogenetics and Evolution 127: 646-654.

https://doi.org/10.1016/j.ympev.2018.06.011 
Ngo H.N., Ziegler T., Nguyen T.Q., Pham C.T., Nguyen T.T., Le M.D. \& van Schingen M. 2016. First population assessment of two cryptic tiger geckos (Goniurosaurus) from Northern Vietnam: Implications for conservation. Amphibian \& Reptile Conservation 10 (1): 34-45.

Ngo N.H., Le Q.T., Pham L.M., Le D.M., van Schingen M. \& Ziegler T. 2019a. First record of the Cat Ba tiger gecko, Goniurosaurus catbaensis, from Ha Long Bay, Quang Ninh Province, Viet Nam: Microhabitat selection, potential distribution, and evidence of threats. Amphibian \& Reptile Conservation 13 (2): $1-13$.

Ngo N.H., Nguyen Q.T., Phan Q.T., van Schingen M. \& Ziegler T. 2019b. A case study on trade in threatened tiger geckos (Goniurosaurus) in Vietnam including updated information on the abundance of the endangered G. catbaensis. Nature Conservation 33: 1-19.

https://doi.org/10.3897/natureconservation.32.33590

Nguyen L.T., Schmidt H.A., von Haeseler A. \& Bui MQ. 2015. IQ-TREE: a fast and effective stochastic algorithm for estimating maximum-likelihood phylogenies. Molecular Biology and Evolution 32: 268274. https://doi.org/10.1093/molbev/msu300

Nguyen T.Q. 2011. Systematics, Ecology, and Conservation of the Lizard Fauna in Northeastern Vietnam, with Special Focus on Pseudocalotes (Agamidae), Goniurosaurus (Eublepharidae), Sphenomorphus and Tropidophorus (Scincidae) from this Country. $\mathrm{PhD}$ thesis, University of Bonn, Germany.

Nguyen V.S., Ho T.C. \& Nguyen Q.T. 2009. Herpetofauna of Vietnam. Edition Chimaira, Frankfurt am Main.

Orlov N.L. \& Darevsky I.S. 1999. Description of a new mainland species of Goniurosaurus genus, from the north-eastern Vietnam. Russian Journal of Herpetology 6: 72-78.

Orlov N.L., Ryabow S.A., Nguyen T.T., Nguyen Q.T. \& Ho T.C. 2008. A new species of Goniurosaurus (Sauria: Gekkota: Eublepharidae) from north Vietnam. Russian Journal of Herpetology 15: 229-244.

Posada D. \& Crandall K.A. 1998. MODELTEST: testing the model of DNA substitution. Bioinformatics 14: 817-818. https://doi.org/10.1093/bioinformatics/14.9.817

Qi S., Grismer L.L., Lyu Z.T., Zhang L., Li P.P. \& Wang Y.Y. 2020a. A definition of the Goniurosaurus yingdeensis group (Squamata, Eublepharidae) with the description of a new species. ZooKeys 986: 127-155. https://doi.org/10.3897/zookeys.986.47989

Qi S., Wang J., Grismer L.L., Chen H-H., Lyu Z-T. \& Wang Y-Y. 2020b. The stoor hobbit of Guangdong: Goniurosaurus gollum sp. nov., a cave-dwelling leopard gecko (Squamata, Eublepharidae) from South China. ZooKeys 991: 137-153. https://doi.org/10.3897/zookeys.991.54935

Ronquist F., Teslenko M., van der Mark P., Ayres D.L., Darling A., Höhna S., Larget B., Liu L., Suchard M.A. \& Huelsenbeck J.P. 2012. MrBayes 3.2: efficient Bayesian phylogenetic inference and model choice across a large model space. Systematic Biology 61: 539-542.

https://doi.org/10.1093/sysbio/sys029

RStudio Team. 2018. RStudio: integrated development for R. RStudio, Inc., Boston, MA, USA. Available from http://www.rstudio.com/ [accessed 24 Apr. 2021].

Sexton J.P., McIntyre P.J., Angert A.L. \& Rice K.J. 2009. Evolution and ecology of species range limits. Annual Review of Ecology, Evolution and Systematics 40: 415-436.

https://doi.org/10.1146/annurev.ecolsys.110308.120317

Stuart B.L., Rhodin A.G.J., Grismer L.L. \& Hansell T. 2006. Scientific description can imperil species. Science 312 (5777): 1137. https://doi.org/10.1126/science.312.5777.1137b 
Sterling E.J., Hurley M.M. \& Le D.M. 2006. Vietnam: A Natural History. Yale University Press, New Haven and London.

Swofford D.L. 2001. PAUP* Phylogenetic Analysis Using Parsimony (* and Other Methods), version 4. Sinauer Associates, Sunderland, Massachusetts, USA.

Thompson J.D., Gibson T.J., Plewniak F., Jeanmougin F. \& Higgins D.G. 1997. The CLUSTAL_X windows interface: flexible strategies for multiple sequence alignment aided by quality analysis tools. Nucleic Acids Research 25: 4876-4882. https://doi.org/10.1093/nar/25.24.4876

Vitt L.J., Caldwell J.P., Zani P.A. \& Titus T.A. 1997. The role of habitat shifts in the evolution of lizard morphology: evidence from tropical Tropidurus. Proceedings of the National Academy of Sciences of the United States of America 94 (8): 3828-3832. https://doi.org/10.1073/pnas.94.8.3828

Vu N.T., Nguyen Q.T., Grismer L.L. \& Ziegler T. 2006. First record of the Chinese leopard gecko, Goniurosaurus luii (Reptilia: Eublepharidae) from Vietnam. Current Herpetology 25: 93-95. https://doi.org/10.3105/1345-5834(2006)25[93:FROTCL]2.0.CO;2

Wang Y.Y., Yang J.H. \& Cui R.F. 2010. A new species of Goniurosaurus (Squamata: Eublepharidae) from Yingde, Guangdong Province, China. Herpetologica 66: 229-240. https://doi.org/10.1655/09-046r2.1

Wang Y.Y., Yang J.H. \& Grismer L.L. 2013. A new species of Goniurosaurus (Squamata: Eublepharidae) from Libo, Guizhou Province, China. Herpetologica 69: 214-226. https://doi.org/10.1655/herpetologica-d-12-00084

Wang Y.Y., Jin M.J., Li Y.L. \& Grismer L.L. 2014. Description of a new species of Goniurosaurus (Squamata: Eublepharidae) from the Guangdong Province, China, based on molecular and morphological data. Herpetologica 70: 309-322. https://doi.org/10.1655/herpetologica-d-13-00080

Yang J.H. \& Chan B.P. 2015. Two new species of the genus Goniurosaurus (Squamata: Sauria: Eublepharidae) from southern China. Zootaxa 3980 (1): 67-80.

https://doi.org/10.11646/zootaxa.3980.1.4

Zhou R.B., Wang N., Chen B. \& Liang B. 2018. Morphological evidence uncovers a new species of Goniurosaurus (Squamata: Eublepharidae) from the Hainan Island, China. Zootaxa 4369 (2): 281-291. https://doi.org/10.11646/zootaxa.4369.2.8

Zhu X.Y., Chen G.Y., Román-Palacios C., Li Z. \& He Z.Q. 2020a. Goniurosaurus gezhi sp. nov., a new gecko species from Guangxi, China (Squamata: Eublepharidae). Zootaxa 4852 (2): 211-222. https://doi.org/10.11646/zootaxa.4852.2.6

Zhu X.Y., Shen C.Z., Liu Y.F., Chen L., Li Z. \& He Z.Q. 2020b. A new species of Goniurosaurus from Hainan Island, China based on molecular and morphological data (Squamata: Sauria: Eublepharidae). Zootaxa 4772 (2): 349-360. https://doi.org/10.11646/zootaxa.4772.2.6

Ziegler T., Nguyen T.Q., Schmitz A., Stenke R. \& Rösler H. 2008. A new species of Goniurosaurus from Cat Ba Island, Hai Phong, northern Vietnam (Squamata: Eublepharidae). Zootaxa 1771: 16-30.

https://doi.org/10.11646/zootaxa.1771.1.2

Manuscript received: 16 November 2020

Manuscript accepted: 3 March 2021

Published on: 31 May 2021

Topic editor: Rudy Jocqué

Desk editor: Pepe Fernández 
Printed versions of all papers are also deposited in the libraries of the institutes that are members of the EJT consortium: Muséum national d'histoire naturelle, Paris, France; Meise Botanic Garden, Belgium; Royal Museum for Central Africa, Tervuren, Belgium; Royal Belgian Institute of Natural Sciences, Brussels, Belgium; Natural History Museum of Denmark, Copenhagen, Denmark; Naturalis Biodiversity Center, Leiden, the Netherlands; Museo Nacional de Ciencias Naturales-CSIC, Madrid, Spain; Real Jardín Botánico de Madrid CSIC, Spain; Zoological Research Museum Alexander Koenig, Bonn, Germany; National Museum, Prague, Czech Republic.

\section{Supplementary files}

Supp. file 1. Supplementary tables. https://doi.org/10.5852/ejt.2021.751.1379.4325

Table S1. Pair-wise genetic divergence between species included in this study.

Table S2. Morphological (minimum-maximum (mean \pm standard deviation)) and meristic characters (minimum-maximum (number of specimens)) of four tiger geckos in Vietnam (except Goniurosaurus araneus). Length given in $\mathrm{mm}$.

Supp. file 2. Supplementary figures. https://doi.org/10.5852/ejt.2021.751.1379.4327

Fig. S1. Snout-vent length (SVL) of four tiger geckos in Vietnam including Goniurosaurus catbaensis, Goniurosaurus huuliensis, Goniurosaurus lichtenfelderi, Goniurosaurus luii. A. Juveniles. B. Adult males. C. Adult females.

Fig. S2. A. Principal component analysis (PCA) on morphological variation amongst four recorded tiger geckos in Vietnam. B. Scatterplots of principal component scores for the first and second principal axes. 